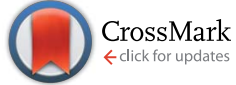

Cite this: J. Anal. At. Spectrom., 2015, 30, 790

Received 25th November 2014 Accepted 4th February 2015

DOI: 10.1039/c4ja00415a

www.rsc.org/jaas

\section{Challenging wax-cast figurine serial production unravelled by multi-analytical techniques $\dagger$}

\author{
Agnès Le Gac, ${ }^{\text {ab }}$ Teresa Isabel Madeira, ${ }^{b c}$ Marco Stanojev Pereira, ${ }^{d}$ Joana Santos, ${ }^{d}$ \\ Luís Piorro, ${ }^{\mathrm{e}}$ Luís Dias, ${ }^{\mathrm{f}}$ Marta Manso, ${ }^{\mathrm{b}}$ Jean Bleton, ${ }^{\mathrm{g}}$ Stéphane Longelin, ${ }^{\mathrm{b}}$ \\ Cátia Marques Prazeres, ${ }^{f}$ José Mirão, ${ }^{f}$ António Candeias, ${ }^{\text {ef }}$ José Gonçalves Marques ${ }^{d}$ \\ and Maria Luísa de Carvalho ${ }^{\text {bh }}$
}

Eight complementary techniques were successfully applied to study a pair of very alike eighteenth-century colored wax figurines belonging to the Museu Nacional Machado de Castro, Coimbra (Portugal): examination under visible and ultraviolet light, X-ray radiography (XRR), neutron radiography and tomography (NR and NT), energy dispersive X-ray fluorescence (EDXRF), scanning electron microscopy coupled with energy dispersive $X$-ray spectroscopy (SEM-EDS), micro-X-ray diffraction ( $\mu$-XRD), gas chromatography coupled with mass spectrometry (GC/MS) and micro-confocal Raman spectroscopy $(\mu-$ Raman). A careful examination of the two objects provided an insight into their manufacturing and revealed that they were cast from the same molds, although details differ. The main cast material employed was a mixture of beeswax, Venice turpentine, other diterpenoid resins and a very low amount of lipids. The wax used was certainly reclaimed from a metallurgic activity involving lost-wax casting. Each figurine consists of sixteen parts, most of which consist of solid wax. The presence of fillings within the body was unexpected. The elements which remained hollowed played a fundamental role at the assembling stage. A loose wooden tenon helped to keep the head in place and metal rods were used to fasten the base to the main body. Polychromy was carried out in wax, with different pigments and opacifiers. The fabrication of the colored wax from different inorganic/organic wastes is also discussed. Textures were achieved by adding materials. The results gathered offered the unique opportunity to verify aspects inherent to the production of multiple copies in wax casting.
${ }^{a}$ Departamento de Conservação e Restauro, Faculdade de Ciências e Tecnologia, Universidade Nova de Lisboa, Campus da Caparica, Quinta da Torre, 2829-516 Caparica, Portugal. E-mail: alg@fct.unl.pt; Fax: +351 21 2948222; Tel: +351 21 2948222

${ }^{b}$ Centro de Física Atómica, Faculdade de Ciências, Universidade de Lisboa, Av. Prof. Gama Pinto 2, 1649-003 Lisboa, Portugal. Tel: +351 21 7904751/2

'Departamento de Física, Faculdade de Ciências, Universidade de Lisboa, Campo Grande, Edificio C8, 1649-003 Lisboa, Portugal. Tel: +351217500975

${ }^{d}$ Centro de Ciências e Tecnologias Nucleares, Instituto Superior Técnico, Universidade Técnica de Lisboa, 2695-066 Bobadela, Portugal. Fax: +351 21994 6016; Tel: +351 21 9946000

${ }^{e}$ Laboratório de José de Figueiredo, Direção Geral do Património Cultural, Rua das Janelas Verdes 37, 1249-018 Lisboa, Portugal. Tel: +351213934200

${ }^{f}$ Laboratório Hércules, Universidade de Évora, Palácio do Vimioso, Largo Marquês de Marialva 8, 7000-809 Évora, Portugal. E-mail: hercules@uevora.pt; Tel: +351 266 740800

${ }^{g}$ Laboratoire d'Études des Techniques et Instruments d'Analyse Moléculaire, Institut Universitaire de Technologie d'Orsay, Université Paris-Sud, Plateau de Moulon Bâtiment 602, 91400 Orsay, France.E-mail: letiam.iut-orsay@u-psud.fr; Tel: +33 (o) 169336130

${ }^{h}$ Departamento de Física, Faculdade de Ciências e Tecnologia, Universidade Nova de Lisboa, Campus da caparica, Quinta da Torre, 2829-516 Caparica, Portugal. Fax: +35121 2954461; Tel: +351212948576

$\dagger$ Electronic supplementary information (ESI) available. See DOI: 10.1039/c4ja00415a

\section{Introduction}

The particular physical and chemical properties of beeswax, such as its malleability with warmth and workability at low temperature, ${ }^{1}$ its accuracy when modelled and very low shrinkage when cast, ${ }^{2}$ its capacity to be mixed with resins and lipids and to be colored, ${ }^{1-3}$ its hydrophobic quality and relative stability over time, ${ }^{4,5}$ justify the interest shown over centuries by artists who chose to adopt this material to shape, by modelling or molding, a wide variety of figures and portraits. In Europe, in the 18th century, the production of long-lasting wax-cast sculptures was based on a long artistic tradition..$^{1-4,6,7}$

The study of two very similar figurines belonging to the Museu Nacional Machado de Castro collection in Coimbra, Portugal (Inventory numbers E657 and E658) offered the unique opportunity to verify aspects inherent to the techniques employed in the production of multiple copies in wax casting, in the 18th century. ${ }^{8}$ Both artworks are absolutely identical from an iconographic perspective and very alike as to the general shape. They represent Francis of Assisi in the round as an emaciated Lesser Brother living in poverty, clad in a rough homespun garment and barefoot. The Stigmata he received in 
1224, two years before his death, are visible. Each figurine stands on a cylindrical pedestal imitating marble, achieved with a blue (E657) or a red veining (E658), and the two bases are framed by Rococo motifs. The style, aesthetic and intimate characters of the statuettes suggest that they belong to the second half of the 18 th century $^{9}$ (Fig. 1).

The artworks measure $c a .30 \mathrm{~cm}$ in height. Both are made of colored wax of multiple sections. The two statuettes would be the exact replica of each other if it were not for certain features that make them easy to distinguish one from another.

Very little is known about the circumstances that brought the two figurines together. In pursuit of art historical information, they are challenging because they were decontextualized. Both artworks entered the museum collection in 1915-16, after a decree was passed, in 1834, disbanding all religious orders in Portugal. The initials 'S.C.' still labeled on one figurine's base (E657), which correspond to the abbreviation of 'Santa Clara' (Fig. 2a), helped at least to indicate the provenance of the two statuettes from the Monastery of St. Claire, located in Coimbra and rebuilt in 1696. No records on their commission and authorship have been found yet, and above all, no information about their context of production came down to us. What makes the connection between these statuettes so exceptional is that they have undoubtedly been cast from the same model.

In order to investigate their raw materials and technology, a goal oriented search using modern analysis techniques was undertaken. The selected techniques included: portable digital

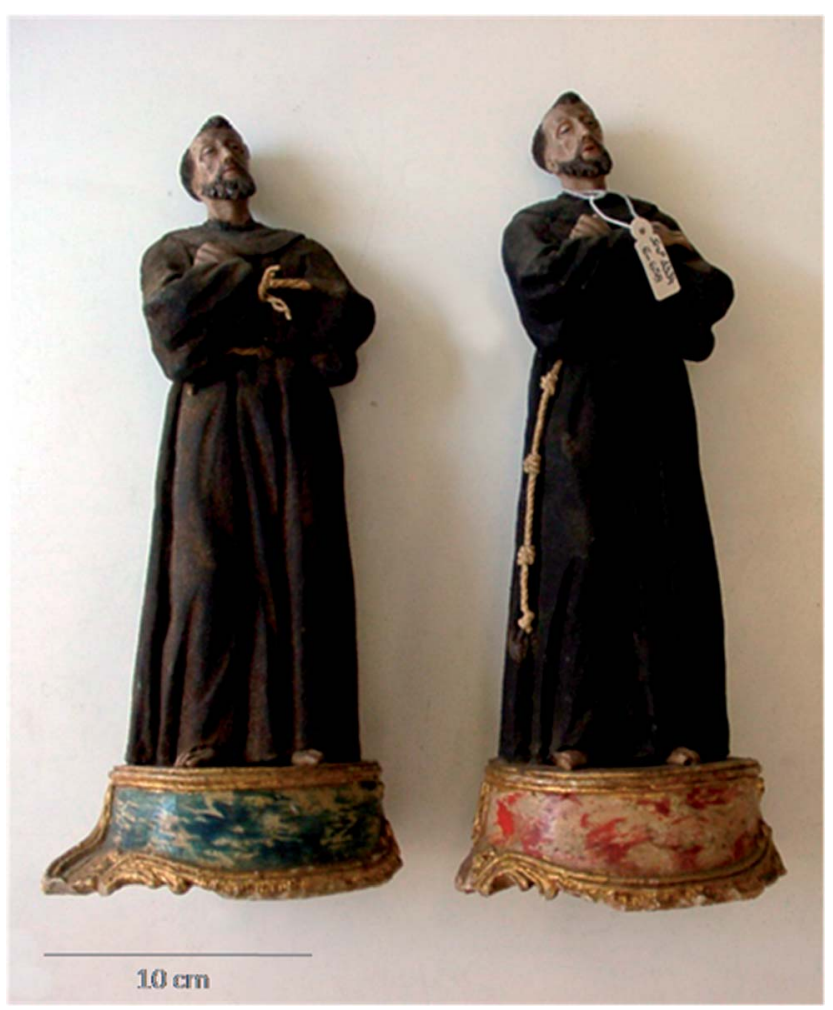

Fig. 1 Pair of eighteenth-century wax-cast figurines hold by Museu Nacional Machado de Castro: Figurine E657 with a blue veined marble; Figurine E658 with a red veined marble - scale bar: $10 \mathrm{~cm}$.
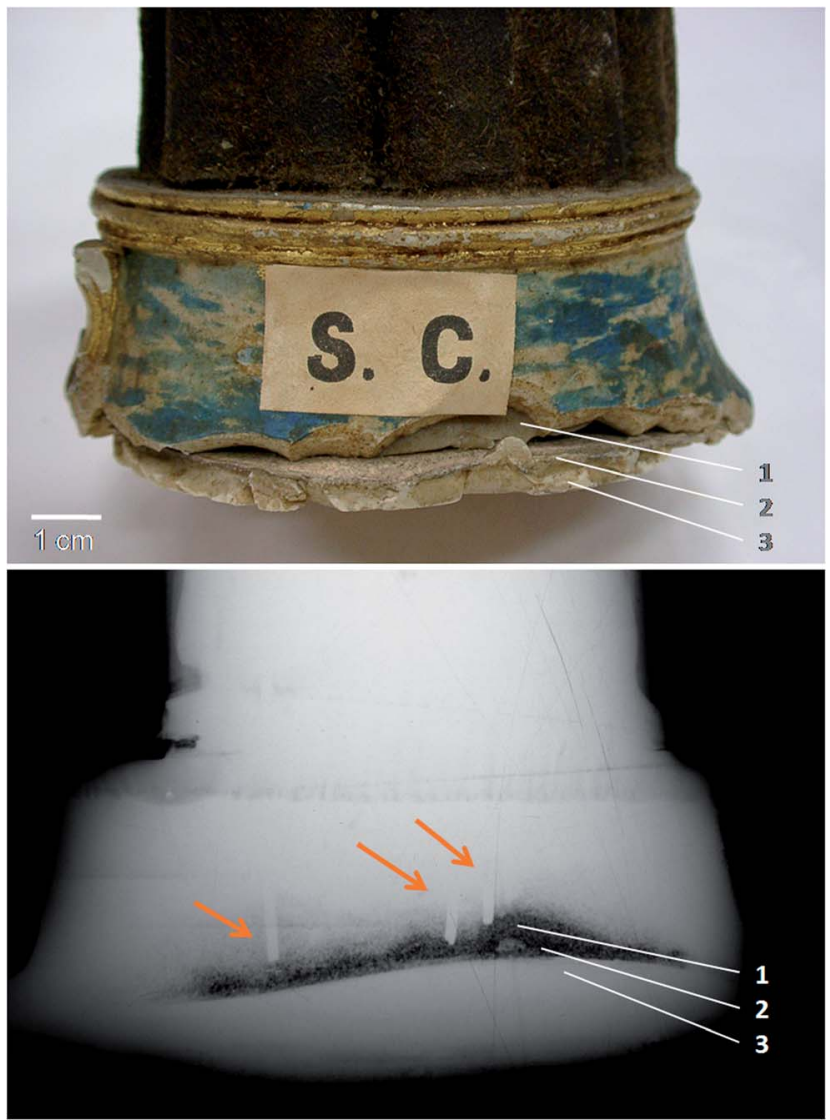

Fig. 2 Pedestal of figurine E657: (a) macrograph in visible and direct light; (b) enlargement of the X-ray image obtained at $40 \mathrm{kV}, 60 \mathrm{~mA}$, $600 \mathrm{~s}$ and $2 \mathrm{~m}$ (object-X-ray source distance) - scale bar: $1 \mathrm{~cm}$. Legend: 1 - second batch of wax used to strengthen the hollowed base; 2 - cardboard; 3 - final white lead-rich coating applied to the figurine's bottom. Orange arrows: iron rods partly visible.

$\mathrm{X}$-ray radiography (XRR), neutron radiography and neutron tomography (NR and NT), portable energy dispersive X-ray fluorescence (EDXRF), scanning electron microscopy coupled with energy dispersive spectroscopy (SEM-EDS), micro-X-ray diffraction ( $\mu$-XRD), gas chromatography/mass spectrometry (GC/MS) and micro-confocal Raman spectroscopy ( $\mu$-Raman).

XRR and NR are non-invasive and complementary techniques used in Art and Cultural Heritage. ${ }^{10}$ Both enable the assessment of objects' internal structures as these techniques are based on the principle of attenuation of radiation by matter: while the former detects high- $Z$ elements, the latter is sensitive to low- $Z$ elements. $X$-rays are electromagnetic radiation, which interacts with matter by three processes: photoelectric effect, Compton or pair production depending on the energy of the incoming radiation, and the atomic number of the atoms. Neutrons are particle radiation and interact through collisions with the nucleus of the atoms. Atoms with low $Z$ such as hydrogen have a higher interaction cross-section, which means that the lower the penetration depth the lower the atomic number and vice versa..$^{10-12}$

With regard to NT, the technique relies on the computation of transmission images from different viewing angles and is 
used to reconstruct virtual cross-sectional transaxial images of the inner structure of the examined object. ${ }^{13}$

EDXRF is also a well-established technique in Cultural Heritage studies as a non-destructive suitable tool for elemental characterization, being applied to all sorts of artworks. ${ }^{14-17}$ This is an elemental technique, based on the ionization of the atoms of the samples by an X-ray source. Nowadays, portable EDXRF spectrometers are available, enabling in situ non-destructive analysis and an unlimited number of measurements since no sampling is needed. The drawbacks of this technique are the low efficiency for light elements and only elemental information is given. For these reasons, it is necessary to complement the obtained data by techniques sensitive to light elements, namely to those of organic compounds, and other techniques for molecular information. Prior to any sampling, EDXRF is the preferred technique as a starting point of the study. ${ }^{\mathbf{1 4 - 1 7}}$

SEM imaging is well suited because it affords three-dimensional views of surfaces and particles with high magnifications and great depth of focus. SEM-EDS has also proved suitable in the study of samples collected from pictorial layers, whatever the substrate over which they were applied. Besides enabling major element point analysis, this technique can provide elemental mapping, which allows a better understanding of the connection existing between the elements at a molecular level. SEM-EDS is also a valuable technique to afford information on metal coatings, whatever the metal or the alloy analyzed, to determine their quality, thickness and fineness. ${ }^{\mathbf{1 8 - 2 0}}$

GC/MS is another suitable technique for this kind of research. This technique is particularly well adapted for the chemical analysis of complex mixtures and is effective for a large variety of compounds after adapted sample preparation. ${ }^{21}$ After the separation by gas chromatography the compounds are detected by mass spectrometry. The data can be used either as fingerprints to prove the material identity or to obtain structural information and identify individual compounds. Natural waxes, as a specific class of lipids, very stable over time, and natural resins, are of extreme interest in Cultural Heritage. Analytical methods based on both HTGC/MS and GC/MS are regularly used to identify these materials in archaeological findings and artworks. ${ }^{22-26}$

Micro-Raman spectrometry was also selected because it enables the identification of molecules and their functional groups through their spectrum of vibrational modes. This technique is highly effective in identifying unknown materials, both organic and inorganic, since molecular group frequencies and crystal lattice modes lead to unique vibrational spectra for different materials, and even for materials that are compositionally identical but differ in either connectivity. In Raman spectroscopy, photons of a single wavelength interact with the molecules and are either reflected, absorbed or scattered. Relevance is given to the scattered photons: the incident photon interacts with matter and its wavelength is either shifted lower or higher (red or blue shifted, respectively). A Raman spectrometer integrated with an optical microscope enables the analysis of microscopic samples or microscopic areas of larger samples. The advantages are that much less samples are required and certain effects may also be enhanced over very localized regions. As not every molecule or functional group exhibits Raman scattering, factors such as the polarization state of the molecule (which determines the Raman scattering intensity) must be considered. The greater the change in polarizability of the functional group, the greater the intensity of the Raman scattering effect. This means that some vibrational or rotational transitions, which exhibit low polarizability, will not be Raman active. They will not appear in Raman spectra even though they might be present; this is the main limitation of the technique. Raman microscopy has also been used to 'authenticate' painted objects by identifying the palette used in their creation and noting any date-marker pigments. ${ }^{27,28}$ Raman spectroscopy was successfully applied to the characterization of polychrome sculptures. $^{29-31}$

Micro-powder XRD allows the identification of crystalline solids based on their atomic arrangements. It can be used in a small area on the surface of the artifact or in very tiny samples. $^{32}$

\section{Methodology}

In a research study aiming at better understanding the implementation of permanent wax-cast copies produced from a sculpture with a complex shape and a polychrome appearance, there are three main steps that must be taken into account: casting, assembling and finishing. In what concerns casting, the quality of the molding procedure depends greatly on the cast material and its properties, namely its behaviour at the pouring stage and after cooling. Assembling implies to understand well the types of joints that can be used. Finally, in finishing involving polychrome and textured effects on threedimensional artworks, special attention has to be paid to any pigments previously combined with wax to obtain a variety of integral colors, and to any material used afterwards in the surface treatments to reproduce the specific tactile and visual qualities of rough, bright and/or reflective matter.

On one hand, technical literature was consulted to establish the contemporary processes used to cast small and large sculptures. Recipes related to 'modelling wax' were duly noted as these were thought to closely resemble those in usage for molding and for lost-wax casting to duplicate metal artworks from an original model. ${ }^{26,33}$ On the other hand, a multianalytical approach was carried out by means of microscopy and spectroscopic techniques, bearing in mind three objectives: (1) to have an in-depth characterization of the materials and techniques used; (2) to allow for a systematic comparison to be drawn between the two figurines and verify how far their manufacturing processes were the same; (3) to verify whether the concrete results of this case-study are pertinent to the material and technical particulars on wax casting from the 18th century. This was conducted in a two-step procedure, first carrying out non-invasive examination and analysis in situ, and then microscopic optical imaging and analysis at the laboratory, on a selected number of micro-samples collected on well representative areas of the artworks. 
The figurines were recorded at the museum by digital photography with a Nikon Coolpix L120 camera (14.1-megapixel superzoom), sporting a $21 \times$ optical zoom lens $(25-525 \mathrm{~mm})$ and including a $1 \mathrm{~cm}$ macro mode. Records were first gathered under normal illumination in direct and raking light to enlighten the specific state of preservation of each figurine, the range of the obtained colors and effects, their texture and brilliancy; secondly, under ultraviolet (UV) excitation in order to observe the fluorescence the materials may emit under longwave UV, nearby $370 \mathrm{~nm}$. The main observation is that the highly textured frock of St. Francis was obtained by the application of fibers in one of them (E657), and by the use of coarsely ground pigments at the very surface in the other one (E658). The figurines were also weighed on a DHAUS GT8000 portable precision balance (with readability down to $0.1 \mathrm{~g}$ ) and an unexpected result showed that there is a significant difference of weight between them. Although there are a few losses on the figurines' members - in the back of the frocks and in the pedestal edges - that also deviate the figurines from their resemblance, these lacks of matter can hardly justify a difference of more than $100 \mathrm{~g}$ between the two objects. This outcome, which may be related to the specific inner structure of each figurine, will be further discussed. Taking advantage of the aforesaid losses (rather due to handling and mechanical impacts than to chemical deterioration), it was possible to have a first idea of how the figurines were constructed, even though their joints could not be observed. Table 1 summarises the preliminary data concerning the two artworks, identified here according to the museum records: E657 and E658 respectively.

Table 1 Differences between the two figurines E657 and E658

\begin{tabular}{lll}
\hline Characteristics & Figurine E657 & Figurine E658 \\
\hline
\end{tabular}

Size $(\mathbf{c m})$
Slight variations in

size between both artworks

Weight (g)

Difference of $+100 \mathrm{~g}$$$
851.6
$$

Height: 28.5 Width: 12.5

Depth: 10

Height: 30

Width: 12

Depth: 11

\section{Head}

Different inclination

of the saint's head

Base

Marbling of the base

of a different colour

Frock

Different treatment on the frock to rend a rough cloth

\section{Damage}

Breaks and losses
Positioned upwards

Blue veining

Natural fibers

No fibers

Cowl missing Hand missing Girdle missing at reverse

\section{Experimental procedures}

\subsection{Non-destructive study}

3.1.1. Digital $X$-ray radiography and neutron radiography. Digital X-ray radiography (XRR), neutron radiography (NR) and neutron tomography (NT) offered the possibility of looking at the inner structure of both objects. They were considered good complementary tools to assess different densities within wax and material thickness, and to visualize the joints. Front and side views were taken by means of XRR aiming at unveiling the way the distinct parts were cast and hold together, and the type of eyes used to give the figurines their glassy stare. As a nondestructive technique suitable to visualize hydrogen-rich substances and organic artefacts, NT was also performed. Tomographic views were obtained on one of the statuettes for providing a better qualitative analysis through visual inspection of $3 \mathrm{D}$ images, according to the different planes of projection.

With regard to XRR, the X-ray generator used corresponds to an Yxlon Smart 160E X-ray tube operating at $40 \mathrm{kV}, 6 \mathrm{~mA}$ for $300 \mathrm{~s}, 40 \mathrm{kV}, 6 \mathrm{~mA}$ for $600 \mathrm{~s}$ and $60 \mathrm{kV}, 6 \mathrm{~mA}$ for $600 \mathrm{~s}$, at the invariable distance from the object of $2 \mathrm{~m}$. The image contrast was improved by increasing the exposure time and the penetration depth was improved by increasing the beam energy. The digital image capture devices were reusable medium-sized photo-stimulable phosphor plates $(37 \mathrm{~cm} \times 43 \mathrm{~cm})$ that, after being radiated, were scanned by means of a computer's imaging software via the SCANNA Durr NDT-CR 35sec scanner.

In what concerned NR and NT, the tomographic equipment is located at Instituto Tecnológico Nuclear-IST in Sacavém, the only one available in Portugal. It is installed at the thermo column of the Portuguese Research Reactor. It consists of a CCD camera, a scintillator screen connected to a computer which controls the camera and the rotating table on which the samples are placed. The 3D-tomography records were obtained by combining 200 individual images (thomos) every $0.9^{\circ}$. The figurine was examined by means of thermal neutron beams ( $0.025 \mathrm{meV} ; 5 \mathrm{~cm}$ diameter) and positioned as close as possible to the scintillator screen. The software used for image reconstruction consisted of Octopus for the visualization of $3 \mathrm{D}$ images and VG Studio Max for metric measurements.

The thicker parts of the figurine (body and pedestal) provided no useful records inasmuch as they were totally opaque to the neutron radiation. On the other hand, XRR put in evidence high $Z$ materials' inner structures which played a structural role. This will be discussed in the next points.

3.1.2. Portable energy dispersive $X$-ray fluorescence. In a preliminary approach, portable EDXRF was applied in situ to search for elemental compositions of all the constitutive parts and verify the coherency of the results between the figurines.

The spectrometer consists of an Eclipse IV Oxford Instruments X-ray tube $(45 \mathrm{kV}, 50 \mu \mathrm{A}, 2.25 \mathrm{~W}$ max.) with a $\mathrm{Rh}$ anode. The radiation is collimated using a tantalum collimator allowing a $5 \mathrm{~mm}$ diameter beam on the sample, placed at $7 \mathrm{~mm}$ distance from the tube and the detector. The detector is an Amptek XR-100SDD with a $25 \mathrm{~mm}^{2}$ detection area collimated down to $17.12 \mathrm{~mm}^{2}$ and $500 \mu \mathrm{m}$ thick fully depleted, and with a
Cowl missing Fingers missing Toes missing 
12.5 $\mu \mathrm{m}$ Be window. The energy resolution is $140 \mathrm{eV}$ at $5.9 \mathrm{keV}$ and the acquisition system is Amptek DppPMCA. The angle between the incident and emitted beam is $90^{\circ}$. The sample was positioned at the focal point of two laser beams. The X-ray generator was operated at $40 \mathrm{kV}$ and $40 \mu \mathrm{A}$, for $150 \mathrm{~s}$.

A dispersion spectrum obtained on a pure carbon sample shows the presence of low intensity peaks of $\mathrm{Ti}, \mathrm{Ni}, \mathrm{Cu}$ and $\mathrm{Zn}$. These peaks arise from the setup, more likely from inner parts of the X-ray tube (anode, window, collimators, electrostatic lenses, etc.). This was taken into consideration when performing the interpretation of the spectra.

\subsection{Laboratory investigation}

3.2.1. SEM and SEM-EDS analysis. SEM imaging (backscattering electron and secondary electron modes) was undertaken on well representative samples examined in longitudinaland cross-section, for high magnification records $(25-5000 \times)$, chemical contrast and topographical aspects. Area and point analyses were carried out by scanning electron microscopy coupled with energy dispersive spectroscopy (SEM-EDS), equipped with mapping facilities, to provide data on all materials employed to achieve the chromatic effects (inerts, pigments and metal coatings). Particular attention was paid to gilding found on the two pedestals in order to distinguish the kind and fineness of the alloys used. Measurements by SEMEDS were always performed at least three times in the same areas, in order to ensure statistical relevance and allow a comparison to be drawn between the metal coatings of the two statuettes. The quantitative concentrations were not round up to the nearest whole number and two digits were maintained, in order to be as closer as possible to the original carat evaluation.

Examination and analyses were carried out using a Hitachi S3700N variable pressure scanning electron microscope coupled with a Bruker XFlash 5010 SDD detector. Standardless point analysis, compositional map acquisition and data treatment were run on the graphical user interface of the analytical software suite ESPRIT from Bruker. The samples were placed on the sample-holder with double-coated conductive carbon tape. Variable pressure was used to avoid coating. The pressure used was $40 \mathrm{mPa}$ (so secondary electrons were not used), and the beam energy was mainly $20 \mathrm{kV}$.

3.2.2. Micro-X-ray diffraction. Micro-X-ray diffraction ( $\mu$ XRD) was applied to have complementary data on the pigments' phases which could not be performed by other means.

Micro-XRD was performed using a BRUKER AXS D8 Discovery diffractometer with a $\mathrm{Cu} \mathrm{K} \alpha$ radiation source and a BRUKER Lynx Eye one-dimensional detector. Diffractograms were obtained in the interval $5-75^{\circ} 2 \theta$, step of $0.05^{\circ}$, time per step of $1 \mathrm{~s}$. The identification was performed with DIFFRAC.EVA software package using the ICDD PDF X-ray pattern database.

3.2.3. Gas chromatography with mass spectrometry. For high temperature gas chromatography with mass spectrometry (HTGC/MS), the system was composed of a Thermo Scientific TRACE GC Ultra chromatograph coupled to a Thermo Scientific DSQ II quadrupole mass spectrometer. The separation was achieved using a $30 \mathrm{~m} \times 0.32 \mathrm{~mm}$ ZB5-HT capillary column
(Phenomenex), resistant to high temperatures $\left(410{ }^{\circ} \mathrm{C} \max \right)$, coated with $0.1 \mu \mathrm{m}$ of $5 \%$ diphenyl $/ 95 \%$ dimethylpolysiloxane. The carrier gas was helium at a constant flow rate of $2 \mathrm{ml} \mathrm{min}^{-1}$. The injector temperature was $280{ }^{\circ} \mathrm{C}$ and the sample $(1 \mu \mathrm{l})$ was injected in splitless mode $(0.5 \mathrm{~min})$. The oven temperature was programmed from $140{ }^{\circ} \mathrm{C}$ to $390{ }^{\circ} \mathrm{C}$ at $10{ }^{\circ} \mathrm{C} \mathrm{min}$ min- $^{-1}$ and maintained at $390{ }^{\circ} \mathrm{C}$ for $5 \mathrm{~min}$. The MS transfer line and ion source temperatures were $350{ }^{\circ} \mathrm{C}$ and $250{ }^{\circ} \mathrm{C}$ respectively. The mass spectrometer was operated in the electron ionization (EI) positive mode $(70 \mathrm{eV})$ with a scan range from $\mathrm{m} / \mathrm{z} 35$ to 1000 at 2 scans per second.

Samples (typically $1 \mathrm{mg}$ ) were trimethylsilylated with $0.5 \mathrm{ml}$ of BSTFA/pyridine (50/50) for $30 \mathrm{~min}$ at room temperature. The excess of reagent was then removed using a rotary evaporator and the dried residue was dissolved in $1 \mathrm{ml}$ iso-octane.

For GC/MS after acid methanolysis and silylation, the system was composed of a Hewlett Packard HP 5890 chromatograph coupled to a Hewlett Packard HP 5973 quadrupole mass spectrometer. The separation was achieved using a $30 \mathrm{~m} \times 0.25 \mathrm{~mm}$ RTX5-MS capillary column (Restek) coated with $0.25 \mu \mathrm{m}$ of $5 \%$ diphenyl/95\% dimethylpolysiloxane. The carrier gas was helium at a constant pressure of $100 \mathrm{kPa}$. The injector temperature was $300{ }^{\circ} \mathrm{C}$ and the sample $(1 \mu \mathrm{l})$ was injected in splitless mode (0.5 min). The oven temperature was kept at $40{ }^{\circ} \mathrm{C}$ for $1 \mathrm{~min}$, then programmed from $40{ }^{\circ} \mathrm{C}$ to $130{ }^{\circ} \mathrm{C}$ at $10{ }^{\circ} \mathrm{C} \mathrm{min}$ me $^{-1}$ and from $130{ }^{\circ} \mathrm{C}$ to $300{ }^{\circ} \mathrm{C}$ at $2{ }^{\circ} \mathrm{C} \mathrm{min}^{-1}$. The MS transfer line, ion source and quadrupole temperatures were $310{ }^{\circ} \mathrm{C}, 230{ }^{\circ} \mathrm{C}$ and $150{ }^{\circ} \mathrm{C}$ respectively. The mass spectrometer was operated in the electron ionization (EI) positive mode $(70 \mathrm{eV})$ with a scan range from $\mathrm{m} / \mathrm{z} 35$ to 650 at 2 scans per second.

Samples (typically $1 \mathrm{mg}$ ) were taken in $0.5 \mathrm{ml}$ of methanolic $\mathrm{HCl}(0.4 \mathrm{M})$ and heated at $80{ }^{\circ} \mathrm{C}$ for $24 \mathrm{~h}$. Thereafter, $\mathrm{HCl}$ was neutralized by adding pyridine $(5 \mu \mathrm{l})$ and methanol was removed using nitrogen stream. The residue was then trimethylsilylated with $0.5 \mathrm{ml}$ of BSTFA/pyridine $(50 / 50)$ at $80^{\circ} \mathrm{C}$ for $2 \mathrm{~h}$. The excess of reagent was then removed using a rotary evaporator and the dried residue was dissolved in $0.5 \mathrm{ml}$ iso-octane.

3.2.4. Micro-confocal Raman spectroscopy. Micro-confocal Raman spectroscopy ( $\mu$-Raman) was useful as a complementary molecular technique to determine the inert and pigments employed to give the statuettes their final appearance.

Raman spectra of the coloring materials were recorded on micro-samples by means of a Horiba-Jobin Yvon Xplora confocal spectrometer, using a $785 \mathrm{~nm}$ laser diode and an entrance slit of $100 \mu \mathrm{m}$. The collected scattered light was dispersed by a 1200 lines $\mathrm{mm}^{-1}$ grating onto an air cooled CCD array of an AndoriDus detector. A $100 \times$ magnification objective with a pinhole of $300 \mu \mathrm{m}$ was used to optimize the spatial resolution and the Raman intensity. Particles of pigment were selected with the help of a microscope. To achieve an accurate identification of the materials under study, a polynomial baseline correction was carried out on the obtained Raman spectra to remove the fluorescence contribution. The identification of pigments was made with accuracy by using the literature ${ }^{34-37}$ and several spectral databases (Crystal Sleuth, Spectral ID) implemented with some of our own references' spectra (pigments provided by Kremer). 


\section{Results and discussion}

As previously referred, the figurines were cast from an original three-dimensional model. As this has not come to light, its material composition is unknown. Models could have been made in a variety of materials, such as carved wood, plaster, clay, wax or cast metals. ${ }^{1-4,6,7}$ For multiples which show slight changes in form, it is likely that either a clay or wax prototype, freshly modelled by hand, would have been used. It is easy to simplify the shape of such works made of tender materials prior to their casting, by simply cutting off any protruding parts and by casting them separately, as independent components.

The complex shape of the artworks under study induced that their casting was based on a rationalized sectioning of the model to avoid undercuts. It is noteworthy that it allowed also the use of different colored waxes, the shade of which would depend on the element to be reproduced: pink for an uncovered part of the body, brown for the cloth and mainly white for the pedestal.

\subsection{Casting}

Each sculpture is a sixteen-parted artwork. Ten parts were used to build up Francis' shape: the habit, the fall of the cowl, the cowl itself (lost in both artworks), the head, both arms, hands and feet (Fig. 1 and 3); three were needed for the pedestal: the cylinder forming the base and the bottom edge made of cardboard and wax (Fig. 2a, layers 2 and 3); the latest three correspond to the knotted cord girdle the friar wears, made of twisted natural fibers imitating a true cord, and the eyes inserted into the face to give a glassy stare (Francis was almost blind in 1224) (Fig. 3, 7a and 8a).

4.1.1. Molds. According to the technological sources, ${ }^{1-4,6}$ it is expected that each section was cast separately by means of a reusable univalve, two-part or multiple-part molds (called ' $a$ bon creux' in French ${ }^{1}$ ) depending on the complexity of each element to be replicated. It is believed that for elements which present a hidden and flat edge - feet and arms - univalve type molds were

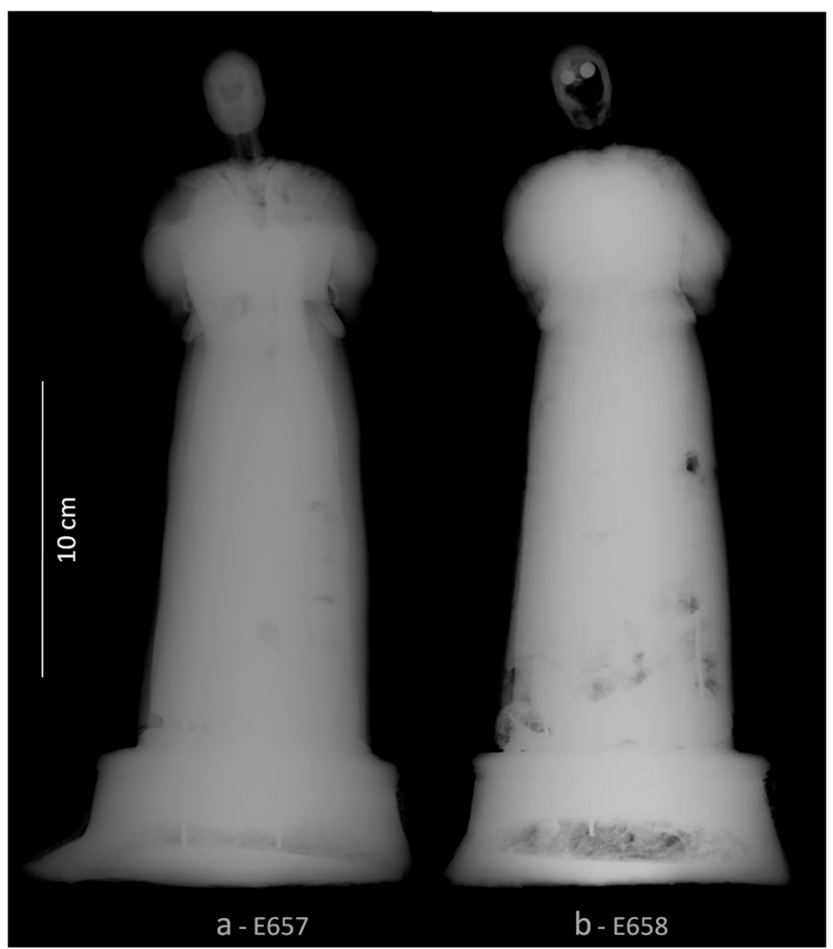

Fig. 4 X-ray image of the pair of figurines E657 and E658 at $40 \mathrm{kV}$, $60 \mathrm{~mA}, 300 \mathrm{~s}$ and $2 \mathrm{~m}$ (object-X-ray source distance).

used, capable of producing the desired shape at once. For the remaining elements created in the round, two-part molds were necessarily employed - if not multiple-part molds - to overcome the undercuts and protrusion issues.

According to the literature, mother plaster or terracotta molds were used. These porous materials would have been dampened to prevent wax from sticking to the mother mold and aid the removal of the cast once set. However, some authors recommended that the inner face of the mother mold, whatever the material used, be coated with a vegetal oil as a release agent. ${ }^{5-7,38,39}$
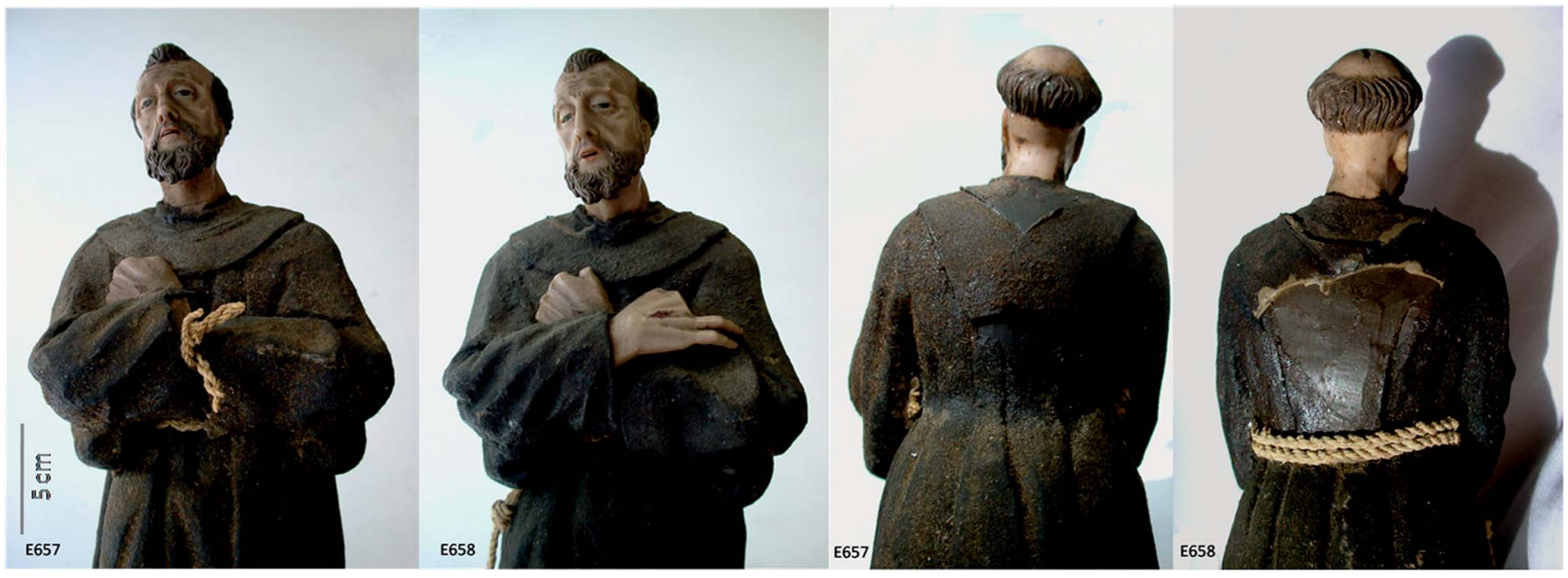

Fig. 3 Pair of eighteenth-century wax-cast figurines. Front and back partial views in direct light - scale bar: $5 \mathrm{~cm}$. 
4.1.2. Solid cast elements. Most of the elements were solid cast. This is the case regarding the smaller parts to give them more durability.

As the main sections and axis of the figurines, the body and pedestal are also solid but they were not cast in one go. They were fabricated in a two-step procedure, by pouring wax ' $a$ volée' to create outer shells, and then wax 'au noyau' to form dense cores and strengthen these structural elements. ${ }^{1}$ The first $\mathrm{X}$-ray radiograph readily showed up a slight difference in contrast between the two figurines imaged in the same condition, and inhomogeneous cast of the saint's body with some regions denser than others (Fig. 4). These two situations, fully justified in a task performed manually, are obviously debatable points which will be further discussed. X-ray images also revealed that, a few millimeters from the figures' outer edges, the inner part is especially dense, full of filings maintained in suspension in the midst of wax. This procedure was put in evidence by increasing the voltage beam of the X-rays, which helped to observe the filings with more accuracy (Fig. 5), definitely opaque to the radiation. Filings are present in several forms: (a) fine and coarse metal powders, resulting from the finishing touches put to any metal piece of work with a file, which leaves an impression of a cloudy substance on the X-ray records; (b) fettled metals, resulting from the clipping - or fettling - of rough hedges in metal-cast works, recognizable by their irregular features; (c) and thin strips of waste metal resulting from line engraving with a burin (supposedly performed on a copper plate for being the favourite metal plate used by engravers up to about 1820), which tend to have a spiral shape. So these filings may have been reclaimed from a wide range of pure metals or alloys, such as iron, copper, tin, lead, zinc, brass alloys, bronze alloys, and even steel (much in use from the late 18th century onwards, when line engraving on steel plates for example became a mechanically assisted manufacture $\left.{ }^{40}\right)$. The accurate chemical composition of the filings could not be determined due to the fact that they are deeply embedded within the objects.

Textual evidence for eighteenth-century artistic practices as to the use of filings in wax was not found in the contemporary literature. ${ }^{7}$ However, it is believed that the use of filings within the figurines may have played several roles: (a) to increase the weight of the statuettes and their stability (hence perhaps the difference already mentioned regarding the global weight of each object - cf. Table 1); (b) to improve the thermal behavior of wax by manipulating its specific heat capacity with that of metals; (c) to increase the wax endurance to cast defects and cracks.

Internal features were also explored using neutron tomography which put in evidence the different densities of the wax, not only from different image transparency but also from the pseudocoded coloration. From these, it was possible to infer the theory on the casting technique 'à la volée' in which a different density between the outer wall and the core is observed. Also, spotty darker structure observed at the torso-level (Fig. 6) suggests that the molten wax used for the core did not consolidate homogeneously, not only due to the presence of the filings but also to the potential formation of air bubbles at the pouring stage.

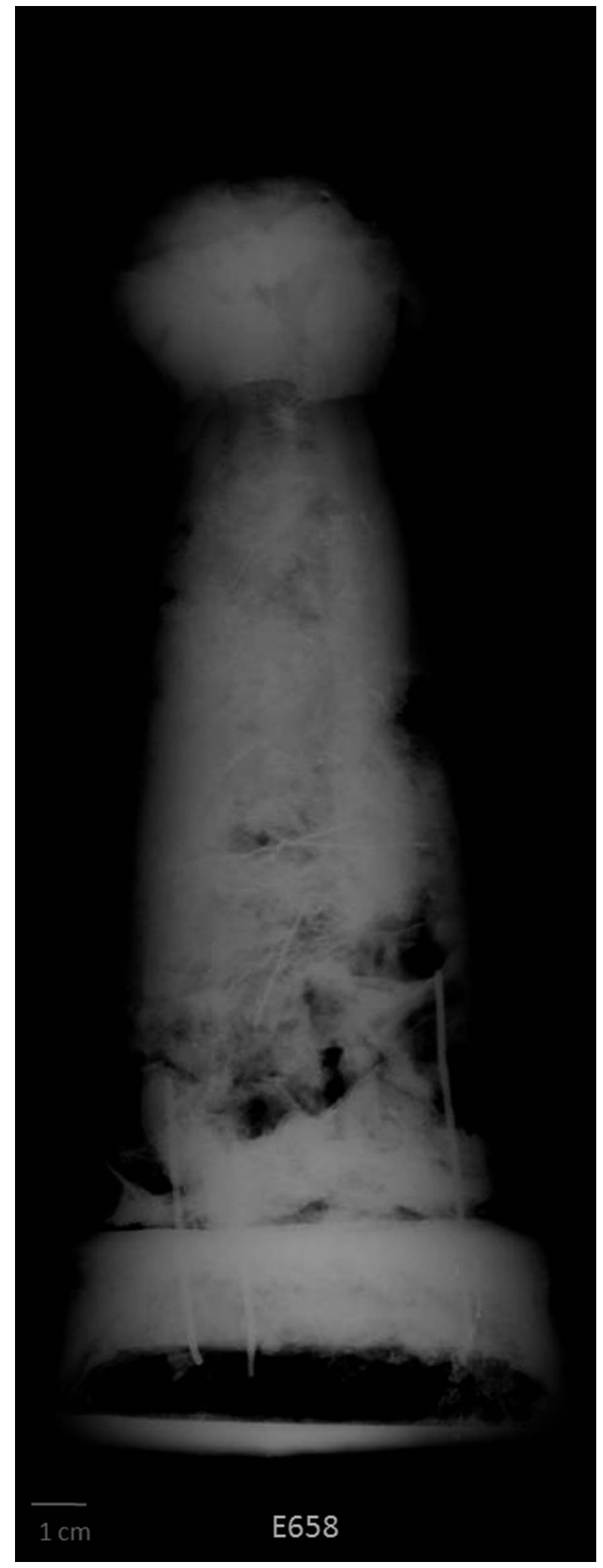

Fig. $5 \mathrm{X}$-ray image of figurine E658 obtained at $60 \mathrm{kV}, 60 \mathrm{~mA}, 600 \mathrm{~s}$ and $2 \mathrm{~m}$ (object-X-ray source distance) - scale bar: $1 \mathrm{~cm}$.

4.1.3. Half-void element. The base was also manufactured following the procedure already described for the body. The pedestal was first cast 'à la volée' to form an outer shell of a 
predominant white (E657) or pale pink color (E658), deliberately bright to get an appropriate basis for imitating marble (Fig. 2a and 11). This hollowed cast element, close on the top, was used at this stage to fasten the saint's body and the base together by means of rods, as discussed below. Only then, the cylindrical volume of the pedestal was reinforced by pouring inside another batch of wax to hold the rods tightly. The base remained half-void, as it was observed in a loss existing on the bottom of the blue veined pedestal (E657). The second batch, partly visible by the naked eye in the aforesaid gap, is made of a waxy substance of a yellow-grayish color, similar to that of unrefined beeswax. Although the outer shell of the pedestal is loaded with white lead (further discussed), X-ray images of both statuettes showed that the upper half of the base has a higher density than the lower half which remained hollowed (Fig. 2b, 4 and 5).

4.1.4. Hollowed cast element. Amongst all the cast element, St. Francis' head is with no doubt the one which was conceived to remain hollowed. X-ray images revealed this particular aspect by increasing the voltage beam as this was

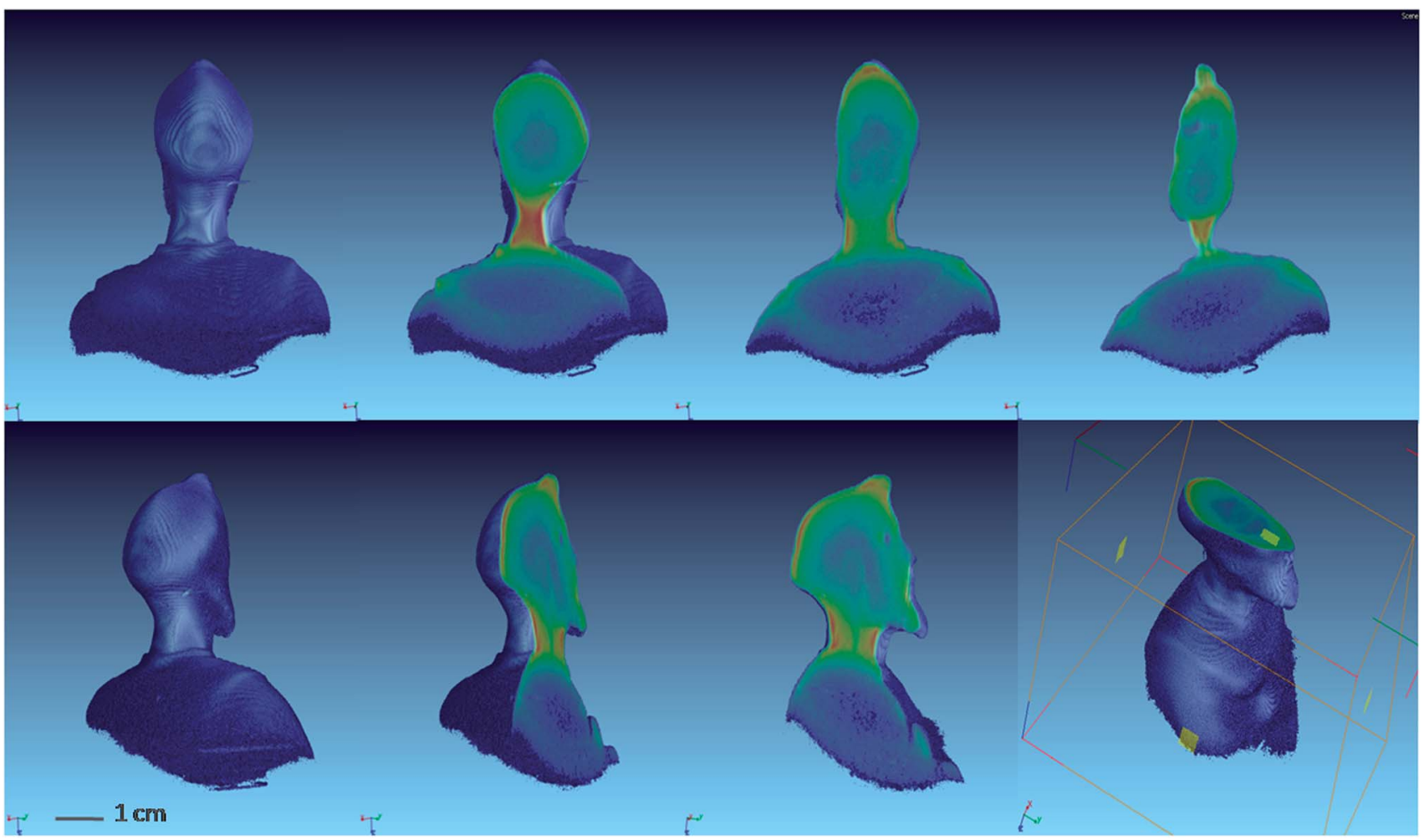

Fig. 6 Ortho-slices of the color-coded images obtained by neutron tomography of figurine E657 and produced from the reconstruction process: (upper row) ortho-slices observed from the coronal direction; (lower row) ortho-slices versus the sagittal and transaxial directions. Scale bar: $1 \mathrm{~cm}$.

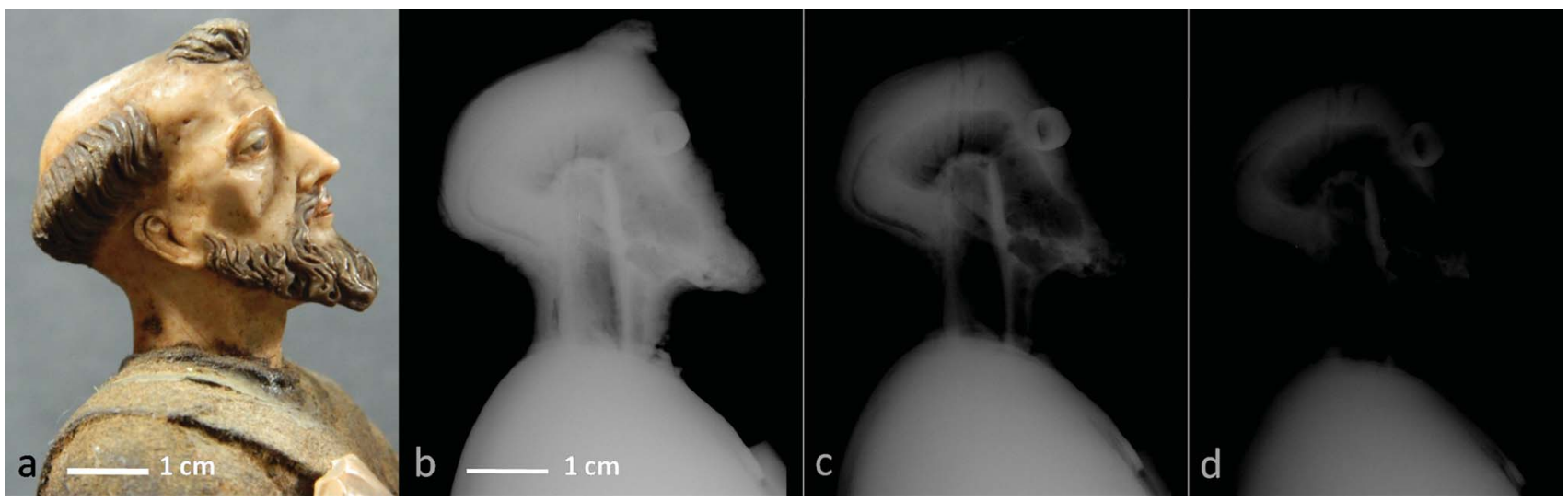

Fig. 7 St. Francis' head in profile, from figurine E657: (a) macrograph in direct light; (b) enlargement of the X-ray image obtained at $40 \mathrm{kV}, 6 \mathrm{~mA}$, $300 \mathrm{~s}$; (c) Idem - at 40 kV, 6 mA, 600 s; (d) Idem - at 60 kV, 6 mA, $600 \mathrm{~s}$ - scale bar: $1 \mathrm{~cm}$. 
performed for unveiling the filings present in the saint's body. Fig. $7 \mathrm{~b}-\mathrm{d}$ and $8 \mathrm{~b}$ illustrate here how detailed were the records obtained by XRR compared to the complementary ones obtained by NR (Fig. 6). Even the voids managed at the mouth and nostril-level are perceived. This depiction is of extreme interest in view of the careful rendering of St. Francis' anatomical features and its considerably reduced dimensions. Here lies one of the most important characteristics of wax for artistic purposes, which is its capacity to afford a remarkable mimetic likeness far surpassing that given by any other materials. It appeared also clearly that the hair were placed afterwards, duplicating the outer walls of the head. After examining

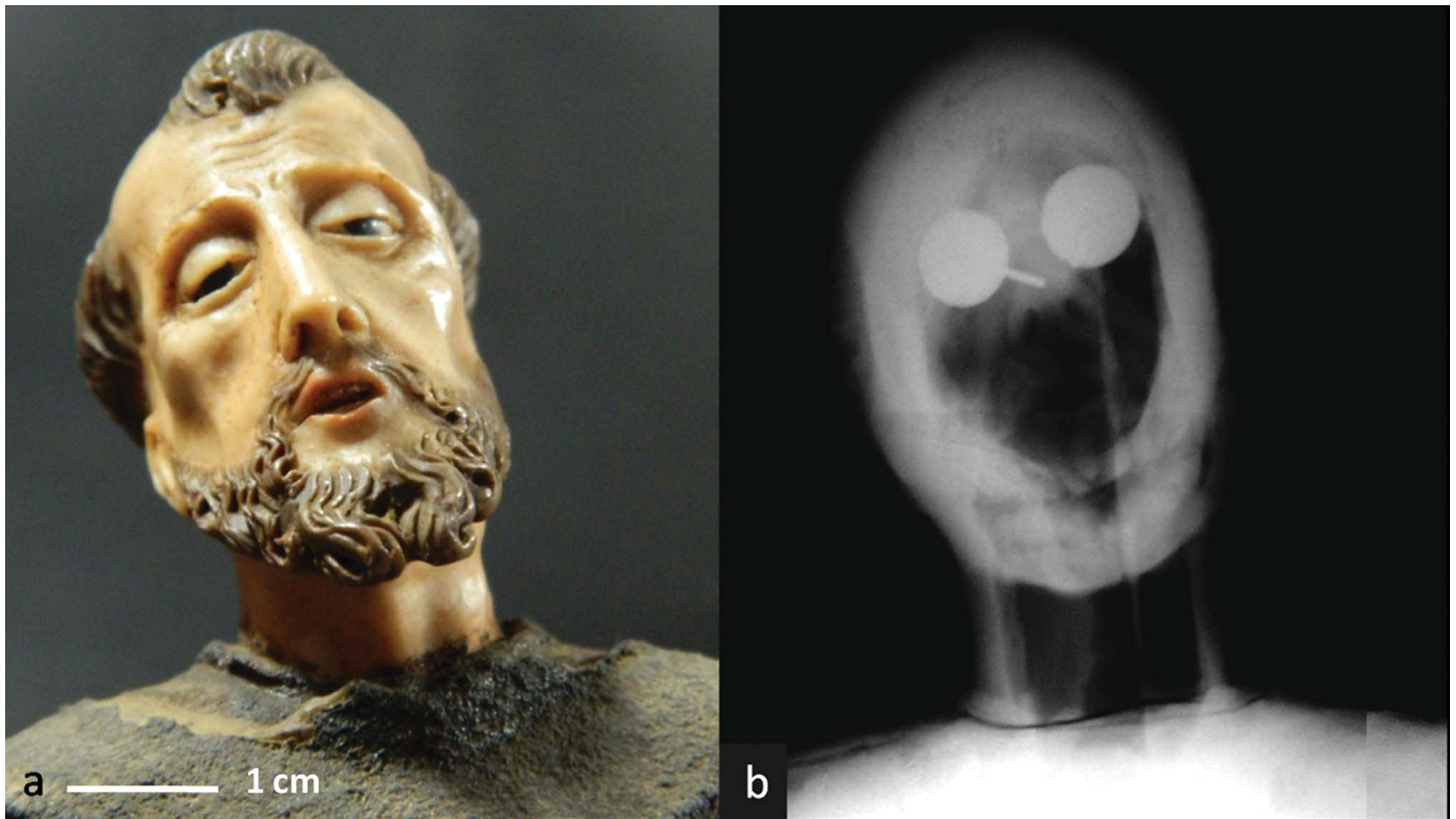

Fig. 8 St. Francis' head front view, from figurine E658: (a) macrograph under visible illumination in direct light; (b) enlargement of the X-ray image obtained at $40 \mathrm{kV}, 6 \mathrm{~mA}, 300 \mathrm{~s}$ and $2 \mathrm{~m}$ (object-X-ray source distance) - scale bar: $1 \mathrm{~cm}$.

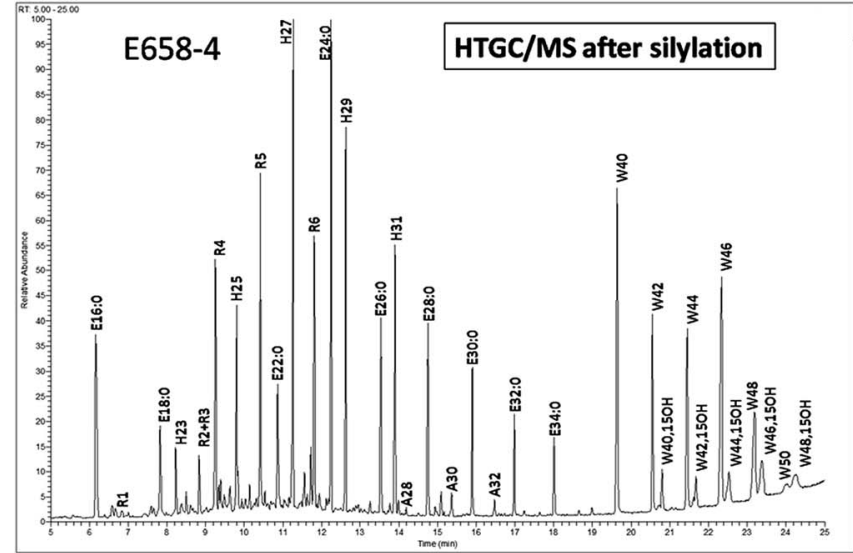

HTGC/MS - Figure 9a - legend

Ex:y : trimethylsilyl Ester of the acid with $\mathbf{x}$ carbon atoms and y unsaturations.

Hx : linear Hydrocarbon with $\mathbf{x}$ carbon atoms

$\mathbf{A x}$ : trimethylsilyl ethers of the alcohols with $\mathbf{x}$ carbon atoms

Wx : wax esters with $\mathrm{x}$ carbon atoms

Wx,15OH : wax esters with $\mathrm{x}$ carbon atoms, hydroxylated on carbon 15 of the acid (trimethylsilylated)

Rx : see table 2

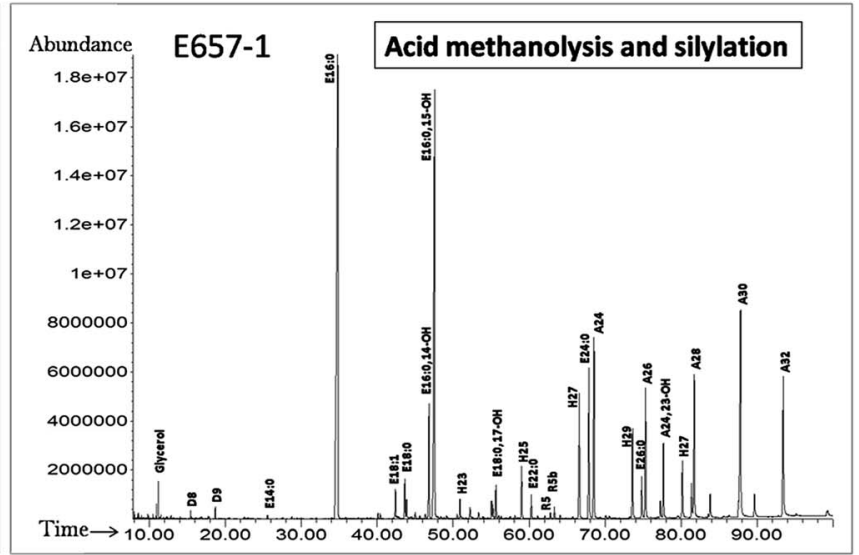

GC/MS - Figure 9b - legend

Dx : dimethyl ester of the Diacid with $\mathbf{x}$ carbon atoms

Ex:y : methyl Ester of the acid with $\mathbf{x}$ carbon atoms and $\mathbf{y}$ unsaturations.

Ex:y,zOH : methyl Ester of the acid with $\mathbf{x}$ carbon atoms and $\mathbf{y}$ unsaturations, hydroxylated on carbon $\mathbf{z}$ of the acid (trimethylsilylated)

$\mathbf{H x}$ : linear Hydrocarbon with $\mathbf{x}$ carbon atoms

Ax : trimethylsilyl ethers of the alcohols with $\mathbf{x}$ carbon atoms

R5a : methyl oxo-7 dehydroabietate

R5b : Trimethylsilyl oxo-7 dehydroabietate

Fig. 9 Chromatograms of samples from figurines E658 and E657, obtained by HTGC/MS and GC/MS respectively. 
the head by NT by multiple view angles, the cross-sectional/ transaxial images of the head were produced using the software Octopus. Fig. 6 presents ortho-slices (in the coronal, sagittal and transaxial directions) of the color-coded images produced from the reconstruction process, where the colors indicate the pseudo-density of the wax-cast head. In this specific case, darker and blue areas indicate regions with a major attenuation coefficient, and orange areas indicate regions with a minor attenuation coefficient. From these images it was possible to observe that the head consisted of different types of structures, such as the void spaces (blue colored areas) including the eyeballs and mouth, and solid parts (orange colored areas) characteristic of the outer shell of the head, particularly well perceived on top of the skull and at the neck-level. Both the 2D slice obtained in black and white, and the corresponding 3D visuals combined with the software VG Studio Max allowed accurate metric measurements of the outer shell walls, of an average thickness of $4 \mathrm{~mm}$.

4.1.5. Cast-material. Micro-samples were taken for GC/MS analysis from different parts of the two figurines. Results indicated that the material employed in casting contain mostly beeswax but also natural diterpenoid resins, more or less oxidized, and a very low amount of other lipids.

The solvent-soluble fraction was analyzed directly by HTGC/ MS after trimethylsilylation. The chromatogram corresponding to a sample collected on the figurine E658 is presented (Fig. 9a) as an example. Identification of beeswax was based on the presence and the distribution of long chain hydrocarbons ( $\mathrm{H} 23$ to H31), trimethylsilyl esters of long chain fatty acids (E22:0 to E34:0), and long chain wax esters (W40-W50).

The markers observed for the resins were the silylated derivatives of epimanool (R1), larixol (R2) and larixyl acetate (R4), characteristic of Venice turpentine exuded from larches

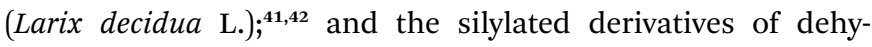
droabietic acid (R3), oxo-7 dehydroabietic acid (R5), and

Table 2 Relative heights of major peaks corresponding to a resin, provided in percentage ${ }^{a}$

\begin{tabular}{llrlrrrl}
\hline Samples & R1 & R2 & R3 & R4 & R5 & R6 & 100\% \\
\hline E657-1 & tr & 1 & tr & 8 & 3 & 1 & E24:0 \\
E657-8 & tr & 2 & tr & 13 & 6 & 4 & E24:0 \\
E658-1 & 2 & 3 & 2 & 36 & 18 & 10 & E24:0 \\
E658-1b & 2 & 3 & 1 & 36 & 11 & 7 & E24:0 \\
E658-2 & 1 & 1 & 2 & 10 & 17 & 13 & H27 \\
E658-3 & tr & 2 & 2 & 10 & 85 & 100 & R6 \\
E658-4 & 1 & 11 & 2 & 52 & 69 & 57 & H27 \\
E658-5 & 1 & 5 & 4 & 44 & 46 & 31 & H27 \\
E658-6 & 1 & 2 & 12 & 18 & 49 & 25 & E24:0 \\
E658-7 & 1 & 1 & tr & 14 & 5 & 3 & E24:0 \\
E658-8 & 1 & 1 & tr & 9 & 5 & 4 & E24:0
\end{tabular}

${ }^{a} \operatorname{tr}=$ trace element. R1: epimanool (silylated). R2: larixol (silylated). R3: trimethylsilyl dehydroabietate. R4: larixyl acetate (silylated). R5: trimethylsilyl-oxo-7 dehydroabietate. R6: trimethylsilyl hydroxy-15-oxo7 dehydroabietate (silylated). E24:0: trimethylsilyl ester of a saturated acid with 24 carbons (wax marker). H27: saturated linear hydrocarbon with 27 carbons (wax marker).
Table 3 Rough amount of larch resin compared to that of wax, provided in percentage ${ }^{a}$

\begin{tabular}{lc}
\hline Samples & $\mathrm{R} 4 / \mathrm{E} 24: 0 \%$ \\
\hline E657-1 & 7 \\
E657-5 & 11 \\
E657-6 & 39 \\
E657-7 & 13 \\
E657-8 & 12 \\
E658-1 & 36 \\
E658-2 & 9 \\
E658-3 & 18 \\
E658-4 & 51 \\
E658-5 & 52 \\
E658-6 & 17 \\
E658-7 & 13 \\
E658-8 & 8 \\
${ }^{a}$ R4: larixyl acetate (silylated). E24:0: trimethylsilyl ester of a saturated \\
acid with 24 carbons (wax marker).
\end{tabular}

hydroxy-15 oxo-7-dehydroabietic acid (R6), common to numerous aged conifer resins.,.$^{\mathbf{4 1 4 2}}$

Estimation of the relative quantities of resins present in the samples was performed for the different pastes (Table 2) using the relative height of each peak corresponding to a resin compared to the one of the major compound. The rough amount of larch resin compared to that of wax was also estimated (Table 3) using the ratio between the height of larixyl acetate (R4) and the major trimethylsilyl ester of the wax (E24:0). The readings revealed that, in the two figurines, both the pedestals (samples E657-1 and E658-7) and the uncovered parts of the bodies depicted with a flesh tone (samples E657-8 and E658-8) are the ones which contain very low amounts of resins, irrespective of their specific origin. As this will be further discussed, these parts of the figurines were certainly made of bleached wax. It is believed that resins were ruled out to avoid any alteration of the light color and brightness of this specific cast material. In contrast, the figurines' body, corresponding to the homespun garment of a dark brown color (samples E658-2, E658-5 and E658-6), readily revealed the high quantities of diterpenoid resins, larch resin and pine resin(s) included. Such a mixture of beeswax and resins was likely prepared to increase the melting temperature of the cast material (the melting temperature of beeswax is about $62-65{ }^{\circ} \mathrm{C}$ ) and its firmness, thus ensuring its better behavior during casting and after cooling, but also its endurance to a warm climate, ${ }^{\mathbf{1 - 4}}$ such as that of Portugal. The major amount of resins within the two samples E658-3 and E658-4 that correspond to the brown layer applied at the very surface of the figurine and the substance employed to keep the girdle in place, respectively, is not surprising. In the former case, it can be perfectly explained by the need to achieve the rough garment with coarsely ground pigment bound in a more resinous medium, and in the latter, to bet on the sticky properties of resins for using them as adhesive.

A preliminary hydrolysis step (methanolysis) was also used to better observe compounds resulting from the oxidation of triglycerides coming from additional oil or fat. The chromatogram 
Table 4 Ratio of azelaic acid to palmitic acid calculated from the peak areas and provided in percentage ${ }^{a}$

\begin{tabular}{ll}
\hline Samples & D9/E16:0\% \\
\hline E657-5 & 1.5 \\
E657-6 & 3.0 \\
E657-7 & 2.2 \\
${ }^{a}$ D9: azelaic acid, E16: palmitic acid. &
\end{tabular}

corresponding to a sample collected on the figurine E657 is presented (Fig. 9b) as an example. Identification of beeswax was based on the occurrence of odd-numbered linear hydrocarbons (H21 to H33), methyl esters of long chain fatty acids (E22:0 to E34:0) and trimethylsilyl ethers of long chain alcohols (A24 to A34) resulting from the cleavage of wax ester bonds, and the presence of very high proportions of palmitic acid. ${ }^{21}$

The presence of a very small amount of other lipids was attested but only indicated by the observation of trimethylsilylated glycerol and methylated $\alpha, \omega$-diacids, with azelaic acid (D9), resulting from the oxidation of triglycerides with unsaturated acid chains, as major compounds. Sterols, very minor compounds, generally used to determine the animal or vegetable origin of lipids, were not detected. Detection of azelaic acid is quite common in oxidized vegetable oils, and its abundance is generally compared to the abundance of palmitic acid $(A / P$ ratio) to determine whether the oil is a drying oil (linseed, walnut or poppy oil for example) or an oil that never dries (olive or almond oil, for example). In the current study, it was not possible to use the $A / P$ ratio to know which kind of lipid was employed because palmitic acid mainly originates from beeswax. In an attempt to compare the relative quantities of wax and of other lipids present in the samples, the ratio of the peak areas corresponding to azelaic acid (D9) and palmitic acid (E16:0) was calculated. To exemplify this procedure, Table 4 provides data for samples E657-05, E657-06 and E657-07. It may not reflect the reality because it presumes that the lipids are of the same nature and in the same oxidation state in all samples. Since they are very low, the amounts are expressed in percentage.

The compiled results showed that, in the long-lasting figurines under study, materials and techniques were not the only aspects at stake. Aesthetical issues (namely the element, the color and the effect to be depicted) were also to be considered, and were managed by adapting the recipes' composition.

Mixtures of beeswax, Venice turpentine and other diterpenoid resin(s) (both in a greater or a lesser quantity), containing also an animal fat or vegetable oil in a very low amount, are consistent with recipes related to 'modelling wax' found in the technical literature..$^{\mathbf{4} 26,33}$ Noteworthy is the fact that most of the written sources dated up to the mid-18th century say nothing about the botanical origin of many substances, which greatly confused matters between resin distillates, fresh secretion of coniferous trees and larch resin (Larix decidua Mill.), since all these compounds were potentially used but designated under the umbrella term of 'turpentine' ${ }^{33}$ At that time, the knowledge of botanists and chemists relied indeed on the unrefined understanding of these products extracted from the Conifer species. In Portugal, recipes that include the specific trade name or marketed product of Venice turpentine are mostly dated from the 19th century onwards. The first mention we found of its use has been published in a later eighteenthcentury Anonymous Portuguese book of recipes. ${ }^{43}$ As most of the formulae were said to have been compiled in earlier sources disseminated abroad, we assume that beeswax-Venice turpentine-based mixtures were used during the 18 th century.

\subsection{Joint techniques}

XRR and NT, whose interaction modes with matter produce in wax-cast artefacts rather specific and complementary results, were used in an attempt to enlighten the joint techniques.

4.2.1. Butt-joint. In the class of organic artefacts under study, a butt joint is the simplest technique used to hold two members of wax together by heating their edges so that they would fuse. This basic joint relies upon the melting point and sticky property of the cast material to butting the members together. Since this joint merely involves the beeswax-resin-based substance used, a perfect assembly along the edges (at cowl-, waist-, shoulder-, arms-, wrist- and ankle-level), could be perceived neither at naked eye nor by XRR, NR and NT (Fig. 3 and 6). This means that no air bubbles remained between the parts hold together and that the assembly was performed very carefully.

4.2.2. Wooden loose tenon. In both figurines, a loose tenon (or dowel pin) was observed at neck-level by XRR (Fig. 7b and c and $8 \mathrm{~b}$ ), NR and NT (Fig. 6). The use of this tenon, based on the principle of the mortise-and-tenon joint, helps to keep the head firmly in place. A mortise likely drilled within the solid torso and the void existing within the head allowed room for the pin to be inserted into them; although in the upper torso the reading of the pin is hidden by the dense surrounding colored wax. The fact that the loose tenon is transparent to X-rays but somehow opaque to neutrons suggests that it is made of wood. Wood is an organic material of a very low atomic weight but also a hydrogen-rich material, mainly composed of cellulose $\left(\left(\mathrm{C}_{6} \mathrm{H}_{10} \mathrm{O}_{5}\right)_{n}\right)$ embedded in lignin (corresponding approximately to the formula $\left.\left(\mathrm{C}_{31} \mathrm{H}_{34} \mathrm{O}_{11}\right)_{n}\right)$. According to the color-coded images and their pseudo-density obtained by NT, and the measurement facilities provided by the software VG Studio Max, it was possible to determine that, in statuette E657, the part of the loose tenon visible inside the head is $25.65 \mathrm{~mm}$ high and has $6.32 \mathrm{~mm}$ in diameter.

4.2.3. Metal rods. The use of three rods that run through the cores of the figure and the base to ensure their adequate holding was observed in both statuettes by XRR (Fig. 2b, orange arrows, and Fig. 5). The higher the penetrative characteristic of the X-ray beam $(60 \mathrm{kV})$ and the exposure time $(600 \mathrm{~s})$, the better the observation of these radiographically dense rods to distinguish them from the surrounding filings (Fig. 5). These rods were introduced within the solid saint's body by the interior of the pedestal while this part was still hollowed. The rods were obviously heated first to pass through both the wax-cast elements closely contacting with one another. Only after cooling were the rods able to play the role of a fastener. Given that the 
X-ray images are life-size, the dimensions of the rods were accurately determined: every rod has $2 \mathrm{~mm}$ in diameter; they are 5.8, 6.6 and 8.4 $\mathrm{mm}$ high in statuette E657; and they are 6.2, 6.4 and $7.0 \mathrm{~mm}$ high in statuette E658. On this basis, it was possible to conclude that all the rods were likely cut from the same metal stick, but in irregular pieces that should only be straight and high enough to provide a strong joint. Each group of three rods proved to be a very efficient and durable type of joint until the present day. As for the filings, the chemical composition of the rods could not be ascertained. As the rods are totally opaque to $\mathrm{X}$-rays compared to the loose tenon under the same conditions of examination, they are likely made of iron. In this type of joint, iron was indeed the metal the most in use in wax-cast objects, ${ }^{39,44}$ since no further risk of corrosion within the anaerobic and hydrophobic wax surroundings was expected.

4.2.4. Auxiliary cardboard. Because the base of statuette E657 was damaged and presents a few losses, its examination at naked eye and imaging by means of digital macrographs helped to observe the use of a cardboard at the bottom, $5.5 \mathrm{~mm}$ thick, to close the opening (Fig. 2a, layer 2). The cardboard was cut to the exact diameter of the pedestal bottom and was further coated by pouring lead white-containing wax over it (Fig. 2a, layer 3). This outer layer, $40 \mathrm{~mm}$ thick, was so perfectly welded to the base circumference that the cardboard underneath remains unsuspected. So if it were not for the gaps existing in the base, this procedure would not be disclosed. The cardboard has an atomic weight too low to be revealed by RXX (Fig. $2 \mathrm{~b}$ and 5) and was not observed by NR because of the pedestal diameter, too large to allow the neutron penetration through the loaded cast material.

\subsection{Polychrome effects}

4.3.1. Marble-like pedestal. As the bases were counterfeiting a white marble in statuette E657 and a light pink marble in statuette E658 (Fig. 1), the use of bleached wax was expected as a cast-material; otherwise, the yellow tone that beeswax has by nature would have predominated in both depictions. This allegation seems to be also sustained by the fact that a very low amount of resins was found in these wax batches (as referred above), likely to avoid any color change by the addition of the yellowish coniferous trees' secretions. Bleached wax is known to have been used for artistic purposes at earlier times, especially in Venice. ${ }^{45}$ Vasari mentioned it in his treatise for producing small objects. ${ }^{39}$ According to Lemery ${ }^{46}$ bleaching was performed by melting and pouring beeswax several times in cold water, by exposing thin portions of wax at sun and dew, and by eliminating any impurities with talc.

The EDXRF analysis showed the presence of $\mathrm{Ca}, \mathrm{S}$ and $\mathrm{Pb}$ in both the white and the pink background of the bases (Fig. 10a and $\mathrm{b}$ ); additionally the element $\mathrm{Hg}$ was found in the pink one (Fig. 10b). The SEM-EDS results provided new information by confirming the association between $\mathrm{S}$ and $\mathrm{Ca}$, and by detecting $\mathrm{Si}$. The results gathered by Raman only allowed the identification of white lead as the main pigment used in the two bases and of vermilion $(\mathrm{HgS})$ to achieve the prevailing pink color in the pedestal E658. This confirmed at least that red lead was not part of the mixture. The additional results gathered by $\mu$-XRD allowed us to accurately assess the use of hydrocerussite (with the chemical formula $\left.2 \mathrm{PbCO}_{3} \cdot \mathrm{Pb}(\mathrm{OH})_{2}\right)$, as the main phase of the white lead pigment employed, and also the presence of high-cristalobalite $\left(\beta\right.$-cristobalite $\left.\mathrm{SiO}_{2}\right)$ in place of quartz $\left(\mathrm{SiO}_{2}\right)$ (Table 5). The latter is a surprising result which came out in every sample analyzed by $\mu$-DRX, irrespective of the colored wax under scrutiny (white pedestal with blue veining, pink pedestal with red veining and brown homespun garment) (Table 5). $\beta$-Cristobalite is one of the high temperature crystalline polymorphs of $\mathrm{SiO}_{2}$. It can originate from high temperature geological environments as thermally metamorphosed sandstones that were previously composed of quartz, or silica-rich volcanic rocks, ${ }^{47}$ but it may also form from quartz sand employed in metallurgical activities. Amongst other purposes, sand is known to have been used as a source material in specific operations such as casting, shaking out, abrasive blasting, fettling, or furnace installation and repair. Cristobalite forms at temperatures about $1470{ }^{\circ} \mathrm{C}$. According to Sandford, ${ }^{48}$ the inversion of the low to the high form of cristobalite occurred at 250 to $260{ }^{\circ} \mathrm{C}$ on heating. In the present case-study, in which casting is a key task, it appears that the presence of $\beta$-cristobalite $\mathrm{SiO}_{2}$ may be related to quartz sand reclaimed from some molding or foundry applications.

4.3.2. Flesh tone. According to the technical literature, ${ }^{39,44-46}$ the flesh tone was obtained by using bleached wax as well and adding mostly two pigments to it: white lead and vermilion in the due proportion to obtain the desired pink color. The very realistic rendering of flesh lies on the fact that bleached wax, slightly colored, reflects light and is capable of imitating to perfection the translucent aspect of the skin; even more in a delicate complexion such as St. Francis'. However, as far as a flesh tone is concerned, the color to be obtained calls for a comparison with recipes found in treatises on painting, ${ }^{49-52}$ insofar as the complexion of different characters could present different hues depending on their gender, age, health circumstances (good, delicate, moribund or dead) and status or holiness, to come up to iconographic issues. So other matters could be admixed to the aforesaid pigments, such as clay minerals, ochers, red lead and black pigments (either of a vegetable or an animal origin).

In situ analysis of the figurines' flesh tone by EDXRF suggested quite complex mixtures. $\mathrm{S}, \mathrm{Ca}, \mathrm{Fe}, \mathrm{Hg}$ and $\mathrm{Pb}$ were systematically detected in both artworks, irrespective of the uncovered part considered (Fig. 10c). Analysis by $\mu$-Raman showed that white lead and vermilion were effectively employed but failed to account for the use of other coloring matters.

4.3.3. Brown foundation materials. A few losses in the surface of the garment revealed at once, at naked eye, that the brown color chosen for each frock was slightly different: of a darker shade in figurine E657 and of a redder brown shade in figurine E658 (Fig. 3). Moreover, in figurine E658, the cowl (broken and fairly lost) showed a beige undertone that would have been determined by the means at the artist's disposal at the time he cast this element. Even so, a comparison between the two figurines' brown frocks, performed by EDXRF, showed no significant differences regarding their elemental compositions (Fig. 10d). As this will be further discussed in the 

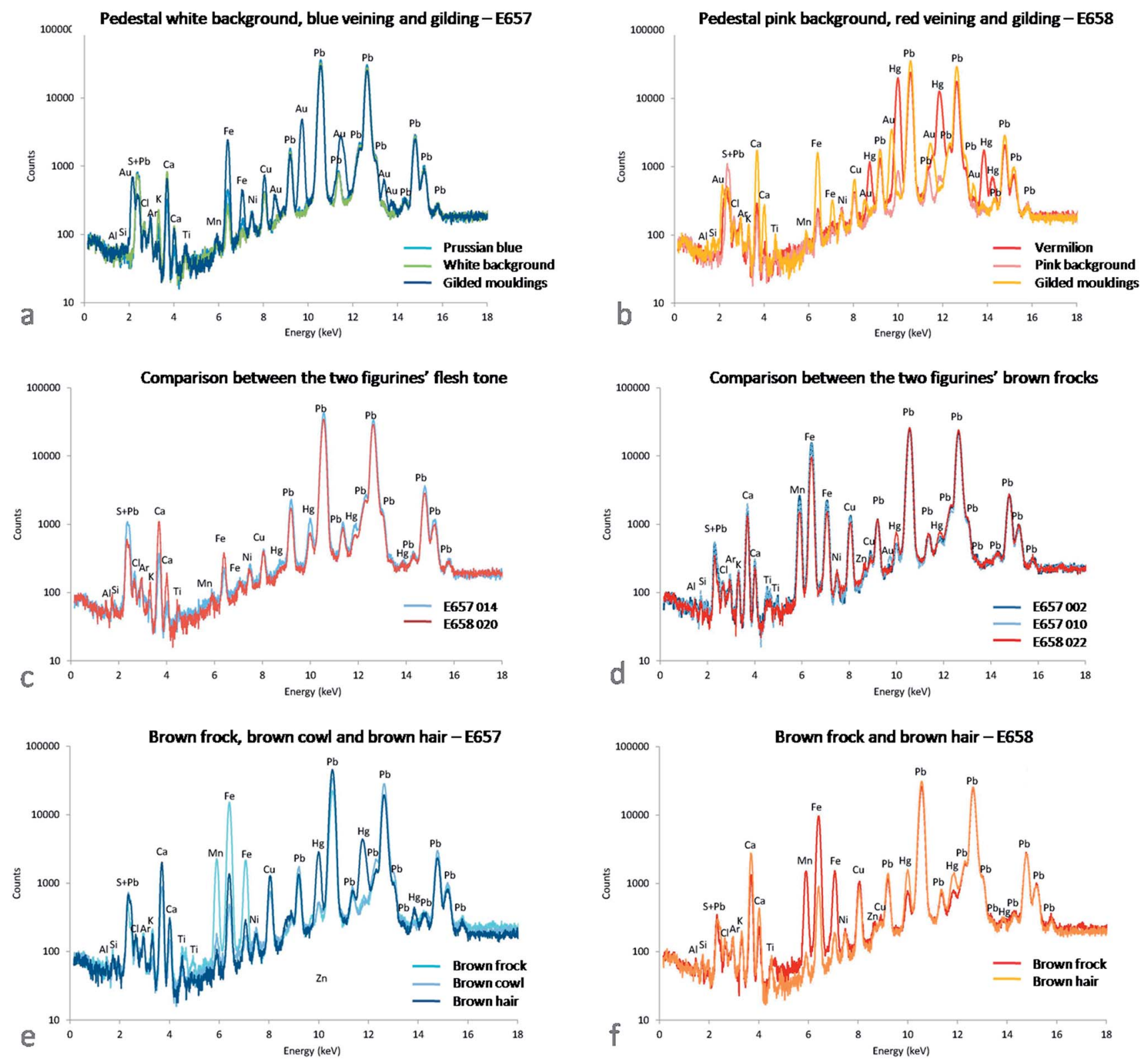

Fig. 10 EDXRF spectra of several colored areas.

Finishing touches, an extra-coat was applied on the garment overall surface of both statuettes to make each frock uniform and the two cast copies very similar.

\subsection{Finishing touches}

4.4.1. Blue veining and red veining. In both artworks, the marbling has been perfected by using a coloring substance, blue or red, bound in wax and applied in its liquid state. Oil of turpentine was certainly added to the mixture to increase fluidity and handling, but it has evaporated. Fluid brushstrokes of 'paint' were applied randomly over the white or pink background as shown in Fig. 11.

Because of the presence of Fe in the EDXRF spectra obtained from the blue veining of pedestal E657 (Fig. 10a), Prussian blue was expected and later confirmed by $\mu$-Raman (Fig. 12). This blue pigment was discovered between 1704 and 1707 and has been widely employed in Europe since 1730-40 onwards. It is clearly quoted in several eighteenth-century books of recipes ${ }^{53,54}$ and its use was verified in polychrome sculptures produced in Portugal, at that time. ${ }^{55}$ Prussian blue is an umbrella term for the blue hexacyanoferrate(II) pigments (compounds based around $\left[\mathrm{Fe}(\mathrm{II})(\mathrm{CN}]^{6}\right]^{4-}$ ) which also contain $\mathrm{Fe}(\mathrm{III})$, and have different compositions, methods of production and adulterations. To such a point that Prussian blue can contain alumina, chalk, ochers and other earths, starch, sulfate of lime and baryta, magnesia, zinc oxide, etc. ${ }^{56-61}$ which was taken into consideration in the present research.

The analysis performed by SEM-EDS revealed a wider range of elements: besides $\mathrm{S}, \mathrm{Ca}, \mathrm{Pb}$ and $\mathrm{Fe}$, the elements $\mathrm{Al}, \mathrm{Si}, \mathrm{Mg}$, 
Table 5 Compounds found by $\mu-X R D$ in colored waxes from both figurines

\begin{tabular}{|c|c|c|c|}
\hline Samples & Ref. code & Compound name & Chemical formula \\
\hline \multirow[t]{4}{*}{ E657-20 blue base } & 00-013-0131 & Hydrocereussite, syn. & $\mathrm{Pb}_{3}\left(\mathrm{CO}_{2}\right)_{2}(\mathrm{OH})_{2}$ \\
\hline & 01-085-0621 & $\beta$-Cristobalite & $\mathrm{SiO}_{2}$ \\
\hline & $00-020-1087$ & Lazurite & $\mathrm{Na}_{8.56}\left[(\mathrm{Al}, \mathrm{Si})_{6} \mathrm{O}_{24}\right]\left(\mathrm{S}, \mathrm{SO}_{4}\right)_{1.56}$ \\
\hline & $01-085-2067$ & Sodalite, syn. & $\mathrm{Na}_{8}\left(\mathrm{Al}, \mathrm{Si}, \mathrm{O}_{4}\right)_{6}\left(\mathrm{Br}, \mathrm{O}_{3}\right)_{1.77}(\mathrm{OH})_{0.23}$ \\
\hline \multirow[t]{4}{*}{ E657-21 brown } & $01-076-2056$ & Cerusssite & $\mathrm{Pb} \cdot \mathrm{CO}_{3}$ \\
\hline & 01-076-0934 & $\beta$-Cristobalite & $\mathrm{SiO}_{2}$ \\
\hline & 01-077-1702 & Lazurite & $\mathrm{Na}_{8.56}\left[(\mathrm{Al}, \mathrm{Si})_{6} \mathrm{O}_{24}\right]\left(\mathrm{S}, \mathrm{SO}_{4}\right)_{1.56}$ \\
\hline & 01-075-1092 & Diopside & $\mathrm{CaMgSi}_{2} \mathrm{O}_{6}$ \\
\hline \multirow[t]{3}{*}{ E658-22 red base } & 00-013-0131 & Hydrocereussite, syn. & $\mathrm{Pb}_{3}\left(\mathrm{CO}_{2}\right)_{2}(\mathrm{OH})_{2}$ \\
\hline & 01-076-0934 & $\beta$-Cristobalite & $\mathrm{SiO}_{2}$ \\
\hline & 01-077-1702 & Lazurite & $\mathrm{Na}_{8.56}\left[(\mathrm{Al}, \mathrm{Si})_{6} \mathrm{O}_{24}\right]\left(\mathrm{S}, \mathrm{SO}_{4}\right)_{1.56}$ \\
\hline \multirow[t]{3}{*}{ E658-23 brown } & 01-076-0934 & $\beta$-Cristobalite & $\mathrm{SiO}_{2}$ \\
\hline & $00-020-1087$ & Hauyne & $\left.(\mathrm{Na}, \mathrm{Ca})_{8}\left[(\mathrm{Al}, \mathrm{Si})_{12}\right] \mathrm{O}_{24}\right]\left(\mathrm{S}, \mathrm{SO}_{4}\right)$ \\
\hline & 01-089-1696 & Hercynite, sun. & $\left(\mathrm{Fe}_{0.781}, \mathrm{Al}_{0.219}\right)\left(\mathrm{Al}_{1.781}, \mathrm{Fe}_{0.219}\right) \mathrm{O}_{4}$ \\
\hline
\end{tabular}

and $\mathrm{Cu}$ were detected in the blue base. By mapping these elements, no relationships between $\mathrm{Al}, \mathrm{Si}$, and $\mathrm{Mg}$ appeared clearly (Fig. 13 - Cu not shown here), which suggests that Al may
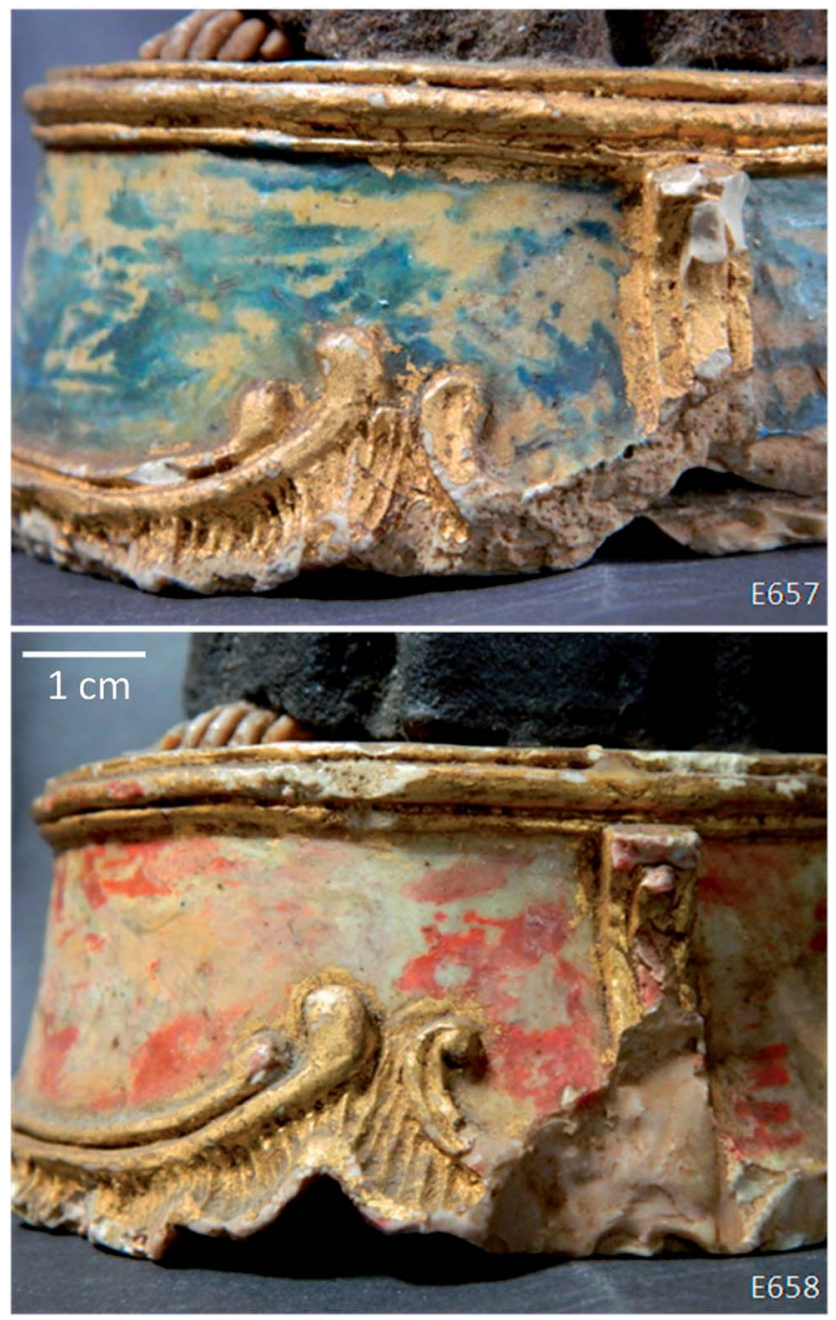

Fig. 11 Marble-like pedestals framed with gilded mouldings: (a) macrograph in direct light of the blue veined base E657; (b) macrograph in direct light of the red veined base E658 - scale bar: $1 \mathrm{~cm}$. be related to some aluminium oxide, namely alumina $\left(\mathrm{Al}_{2} \mathrm{O}_{3}\right)$, and $\mathrm{Si}$ with quartz $\left(\mathrm{SiO}_{2}\right)$. Besides calcite, the mineral corundum and alumina could be encountered in paint as fillers, ${ }^{62}$ so the presence of $\mathrm{Al}$ may be assumed. It should additionally be recalled that alumina could be part of the adulterants used in some Prussian blue compositions, leading in this case-study to an expectation of this matter. In contrast, the presence of aluminium hydroxide, generally used as a substrate for lake pigments, such as indigo for example, was ruled out for indigo was not identified by $\mu$-Raman. Further analyses on individual points were performed in an attempt to sustain the fact that talc, which is a mineral composed of hydrated magnesium silicate with the chemical formula $\mathrm{H}_{2} \mathrm{Mg}_{3}\left(\mathrm{SiO}_{3}\right)_{4}$ or $\mathrm{Mg}_{3} \mathrm{Si}_{4}$ $\mathrm{O}_{10}(\mathrm{OH})_{2}$, could be present by its own. This was hardly assessed, since $\mathrm{Mg}$ and $\mathrm{Si}$ seem to have no connection in elemental mapping. As magnesium was also part of the adulterants found in some Prussian blue preparations, ${ }^{62}$ the presence of $\mathrm{Mg}$ seems justified.

The low detection of $\mathrm{Cu}$ in the pedestal by EDXRF cast doubts about the use or not of a copper-based pigment, such as

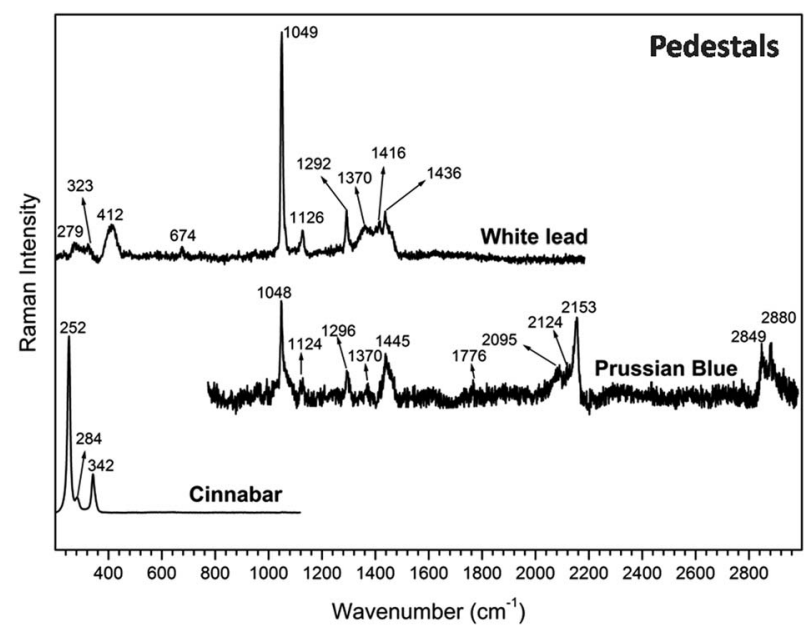

Fig. $12 \mu$-Raman spectra from the marble-like pedestals. 

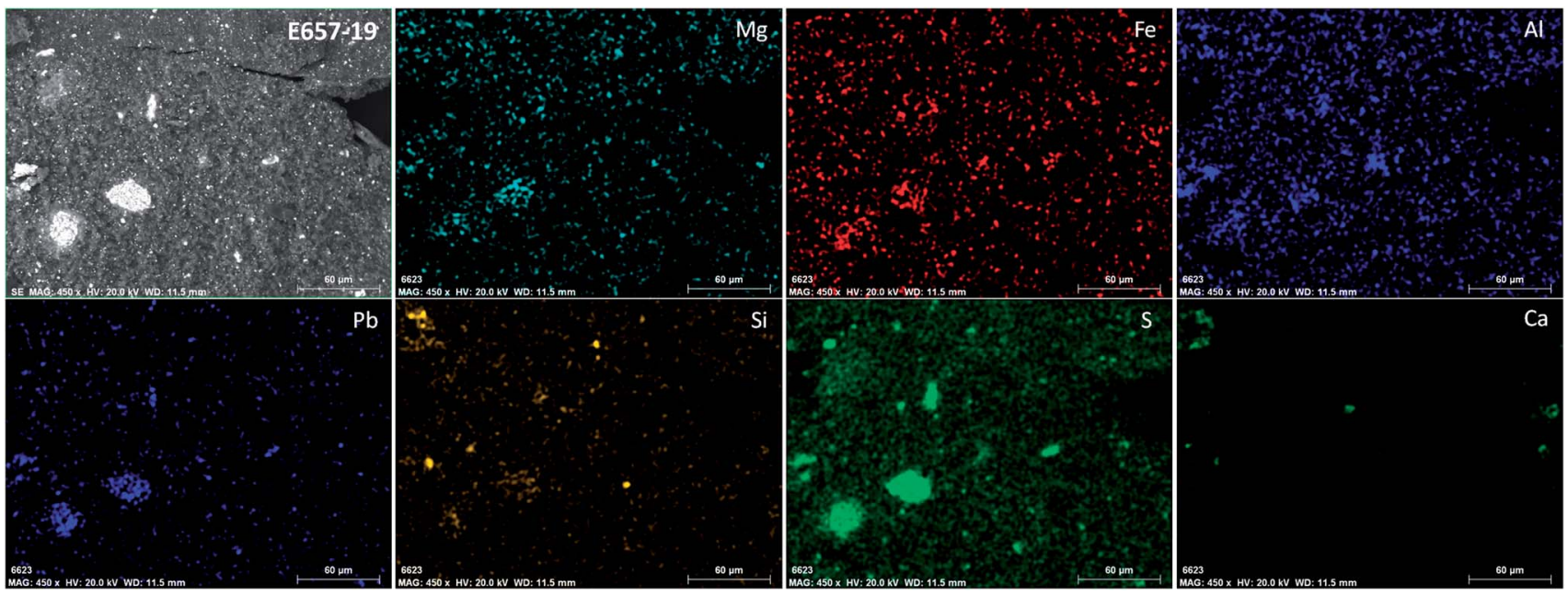

Fig. 13 Blue marble-like pedestal. Planar section of sample E657-19 observed by SEM (BSE mode), 20 kV, $450 \times$, scale bar: $60 \mu$ m; and elemental mapping, including the elements $\mathrm{Pb}, \mathrm{Mg}, \mathrm{Si}, \mathrm{Fe}, \mathrm{S}, \mathrm{Al}$ and $\mathrm{Ca}$.

azurite, a copper carbonate of a blue color with the chemical formula $\mathrm{Cu}_{3}\left(\mathrm{CO}_{3}\right)_{2}(\mathrm{OH})_{2}$. Analysis by SEM-EDS was performed in an attempt to assess if azurite, apart from Prussian Blue, was selected to achieve the veining on the blue marble-like pedestal (statuette E657). Although the results showed in fact the presence of multiple tiny copper-containing particles, it is difficult to be definite on their color and identify them as azurite. Bearing in mind that the finest the grinding of azurite, the highest the pigment loss of color, the tiny size of the particles and their optical properties seem to belie the intention by the artist of coloring the base with a costly blue pigment while this pigment will be poorly perceived. In this particular case, it seems that the detection of $\mathrm{Cu}$ is more likely to be related to a copper-based material, such as the waste copper powder already used as filings within the statuette, or present in the atmosphere of a metalworking workshop.

In an attempt to find more answers, analysis was performed by $\mu$-XRD. Regarding Prussian blue, particles tend to clump in amorphous aggregates so the identification of the pigment by this method was not expected. ${ }^{63}+$ An unexpected result came out from the fact that ultramarine blue was found, not only in the blue color of the veined marble (Table 5, sample E657-20) but also in the other waxes colored pink and brown (Table 5, samples E657-21, E658-22 and E658-23). The crystalline phases of lazurite, sodalite, haüyne and diopside were detected in the diffractograms. Lazurite, the naturally occurring blue mineral and rock type found in lapis lazuli, is a member of the sodalite group. It is a sodic-calcic aluminosilicate sulfate mineral with the chemical formula $(\mathrm{Na}, \mathrm{Ca})_{8}\left[(\mathrm{Al}, \mathrm{Si})_{12} \mathrm{O}_{24}\right]\left(\mathrm{S}, \mathrm{SO}_{4}\right) \cdot{ }^{62}$ Haüyne is

\$ Srivastava and co-workers ${ }^{63}$ demonstrated that, while Prussian blue is synthesized and prepared as a very thin film, the pigment microstructural features at the nano-scale consist mostly of an amorphous phase which contains crystalline structures (nano-grains) in some regions. Under the present conditions of analysis by XRD, since the pigment is embedded in wax and highly dispersed within the organic cast-material, the identification of Prussian Blue was not expected. a feldspathoid mineral which also belongs to the sodalite group, being closely related to lazurite. It has a similar composition and structure to a feldspar but differs in that it contains less silica. Haüyne has composition $(\mathrm{Na}, \mathrm{Ca})_{4-8} \quad\left[\mathrm{Al}_{6} \mathrm{Si}_{6} \mathrm{O}_{24}\right]$ $\left(\mathrm{SO}_{4}, \mathrm{~S}, \mathrm{Cl}\right)_{1-2}$ and is commonly blue in colour, although white haüyne can also be found. ${ }^{62}$ The lazurite artificial variety, called ultramarine, is essentially a three-dimensional aluminosilicate lattice with a sodalite structure containing entrapped sodium ions and ionic sulfur groups. In its simplest form ultramarine has a basic lattice unit of $\mathrm{Na}_{7} \mathrm{Al}_{6} \mathrm{Si}_{6} \mathrm{O}_{24} \mathrm{~S}_{3} .{ }^{62}$ All these compounds possess an identical crystal structure and are hardly distinguishable one from another. At this point, it is advisable to recall that the natural mineral lazurite has been found in European illuminated manuscripts and paintings between the 14 th and the 19 th century, ${ }^{\mathbf{6 4 , 6 5}}$ but it was highly prized and costly. As for the synthetic ultramarine, its systematic fabrication commenced only in the years 1828-1830 after the discoveries by the French Guimet and the German Gmelin of a workable method to intensively produce the pigment. ${ }^{62,65}$ The question of which variety of the blue pigment was employed in the figurines E657 and E658 is obviously a matter of interest. The use of artificial ultramarine would of course imply that the figurines, branded with the Rococo style and presumably cast during the 18th century, would be realizations of a later period, which would question their dating. With regard to the genuine mineral lazurite, it is worth noting that, on one hand, the traditional method to refine lapis lazuli consisted of kneading the coarsely ground mineral lapis lazuli in a dough of molten wax, resins and oil under water or lye of beechwood ashes; the blue lazurite particles were then preferentially washed out and collected, the unwanted minerals largely remaining behind. ${ }^{49,50,66}$

Different stages would thus give grades of variable quality. On the other hand, the intense blue color specific to lazurite is hardly perceived, either at naked eye or by means of a stereomicroscope, in the blue veined pedestal, especially where it was supposed to contribute to the color blue. Therefore, the 
particles of pigment present within the wax would be from a lower grade, and eventually from the poorest, which came to the name of 'ultramarine ashes'. As the pale-colored end-product of multiple extractions from lapis lazuli, ultramarine ashes would mainly consist of diopside, one of the colorless mineral
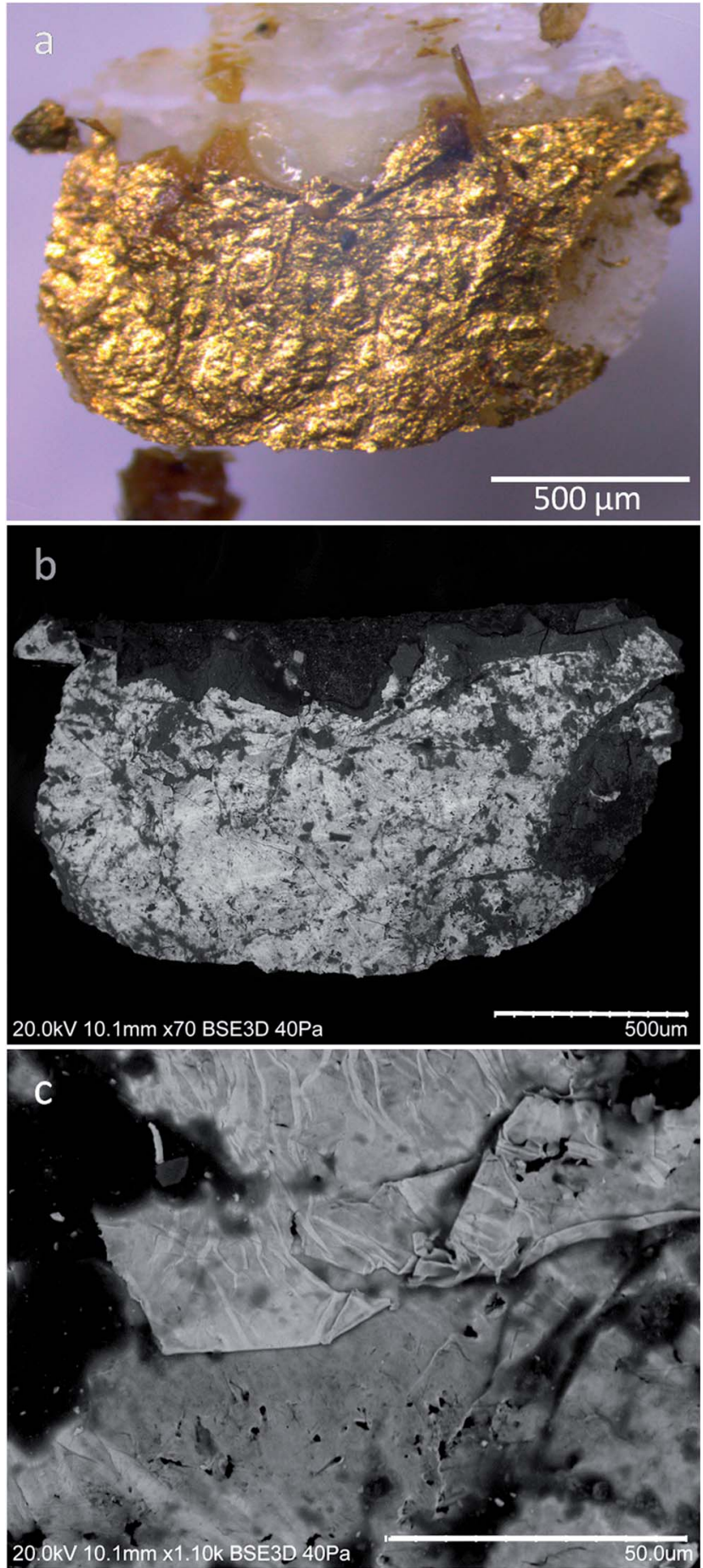

Fig. 14 Matte gilding applied to the mouldings of the base E657: (a) micrographs of sample E657-20 observed in planar section, with a stereo-microscope, scale bar: $500 \mu \mathrm{m}$; (b) SEM record (BSE), $20 \mathrm{kV}$, $70 \times$, scale bar: $500 \mu \mathrm{m}$; (c) SEM record (BSE), 20 kV, 1100×, scale bar: $50 \mu \mathrm{m}$. congeners of lazurite. ${ }^{67}$ So, given (a) the difficulty in visualizing the ultramarine tone in the pedestal (and in any other elements in which lazurite was found); (b) the detection of lazurite and also diopside as mineral impurity associated with the mineral pigment; ${ }^{68}$ and (c) the high chemical compatibility between the traditional 'dough' method (using wax and resin) to obtain different grades of lazurite and the wax-resin-based material employed to cast the figurines, one wonders if waste wax with which lapis lazuli was mixed would have been reclaimed. The remaining lower-grade pigments extracted from it would have been used in the blue color, and the wax itself, further recycled in the present artworks. This would explain the identification of the genuine pigment, intentionally utilized at lower cost in the blue veined marble and inadvertently present in parts diversely colored of the statuettes.

As to the pedestal of the statuette E658, EDXRF results showed that a mercury-based pigment was used to achieve the red pattern (Fig. 10b). The results gathered by $\mu$-Raman confirm that vermilion was the favourite material employed to produce both the pinkish ground and the veining applied over it (Fig. 12). The analysis performed by SEM-EDS revealed the presence of $\mathrm{Si}$ and $\mathrm{Cu}$ in this red base (not provided here). As in the blue pedestal, $\beta$-cristobalite $\mathrm{SiO}_{2}$ was put in evidence by $\mu$-XRD (Table 5, sample E658-22). Whatever the pedestal final color, the analyses provided no valid answer regarding copper. Its presence seems to rely upon the same contaminated environment of a metalworking workshop, as referred for the other figurine.

4.4.2. Matte gilding. The decorative Rococo motifs which frame the two pedestals were achieved with a reflective coating of a yellow metallic luster (Fig. 11). Records obtained from micro-samples observed by stereo-microscopy showed that a gold leaf was laid over a brown translucent substance (Fig. 14a), likely a mordant used in the oil gilding technique. ${ }^{69,70}$ This technique is particularly suitable to gild on wax (due to the high chemical compatibility between oil and beeswax), with the very well-known limit that the gold leaf cannot be further burnished, thus producing a final matte gilding. Records obtained by SEM imaging (BSE) on the samples' longitudinal section (Fig. 14b) confirm that tiny fragments of hand-beaten gold leaf were used to perform the raised gilded surfaces (Fig. 14c). SEM-EDS results

Table 6 Gold alloys' quantitative evaluation ${ }^{a}$

\begin{tabular}{lllllll}
\hline Sample & $\mathrm{Au}(\mathrm{wt} \%)$ & Error & $\mathrm{Ag}(\mathrm{wt} \%)$ & Error & $\mathrm{Cu}(\mathrm{wt} \%)$ & Error \\
\hline E657-20 & 96.13 & \pm 2.68 & 2.12 & \pm 0.11 & 1.75 & \pm 0.10 \\
& 96.10 & \pm 2.99 & 2.31 & \pm 0.13 & 1.59 & \pm 0.10 \\
& 96.69 & \pm 3.09 & 2.05 & \pm 0.12 & 1.26 & \pm 0.09 \\
& 94.85 & \pm 2.67 & 3.81 & \pm 0.16 & 1.33 & \pm 0.09 \\
& 95.61 & \pm 3.03 & 2.28 & \pm 0.12 & 2.12 & \pm 0.12 \\
Average & $\mathbf{9 5 . 8 7}$ & & $\mathbf{2 . 5 1}$ & & $\mathbf{1 . 6 2}$ & \\
E658-22 & 94.11 & \pm 2.59 & 3.28 & \pm 0.15 & 2.61 & \pm 0.13 \\
& 93.32 & \pm 2.53 & 3.96 & \pm 0.16 & 2.72 & \pm 0.13 \\
Average & 93.09 & \pm 2.47 & 4.29 & \pm 0.17 & 2.62 & \pm 0.12 \\
\end{tabular}

${ }^{a}$ Gold content: 23 ct gold alloy $=95.84 \% .22$ ct gold alloy $=91.68 \%$. 

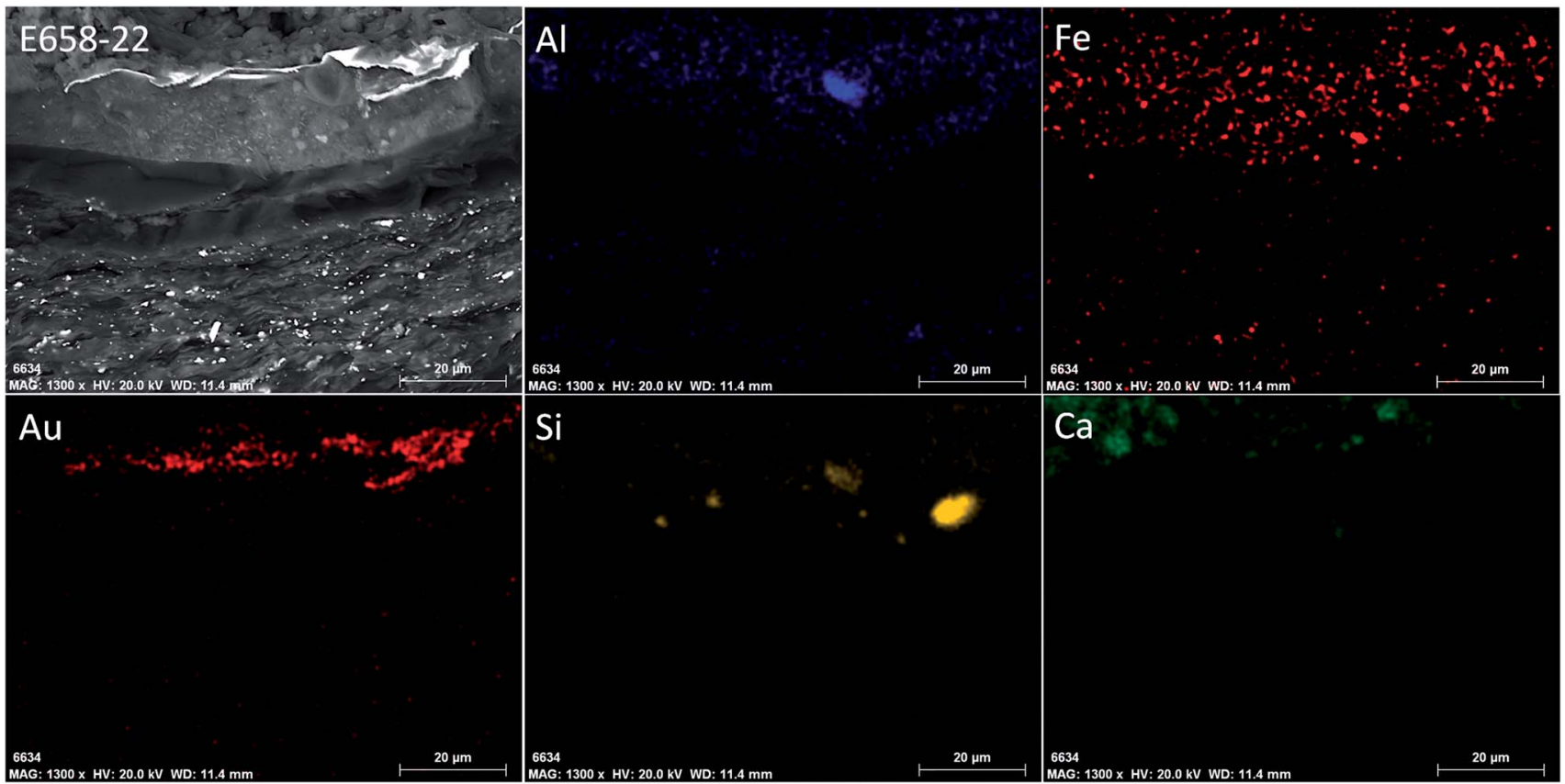

Fig. 15 Matte gilding from the mouldings of the base E658. Cross-section of sample E658-22 observed by SEM (BSE), $20 \mathrm{kV}, 1300 \times$, scale bar: $20 \mu \mathrm{m}$; and elemental mapping of the mordant in which the elements $\mathrm{Al}, \mathrm{Si}, \mathrm{Fe}$ and Ca were detected.

revealed that, in both statuettes, a ternary gold alloy $(\mathrm{Au}-\mathrm{Ag}-\mathrm{Cu})$ was employed (Table 6). On the basis of the quantitative analysis (expressed in percentage of weight - wt\%) done several times on each sample, the gold leaf from the figurine E657 matches a 23 ct gold alloy, and the gold leaf from the figurine E658, a 22.5 ct gold alloy. Although the difference between the two alloys is fairly slight, it is sufficient to affirm that two batches of gold were used. The reason for this occurrence, either due to the access to certain gold products and not others, or to a deliberate choice by the painter-gilder in charge (for an aesthetic or an economical issue, for example), is not clear. In any case, it seems that this result is not fortuitous, since the gold purifying procedures were totally mastered in the second half of the 18th century, and the gold grade was consequently a matter of the utmost control, as much in Portugal ${ }^{71,72}$ as in the neighboring countries. ${ }^{73,74}$

With regard to the substance which allowed the gold leaf to be attached to the bases, its record on a sample cross-section by SEM imaging at high magnification (Fig. 15) allowed inorganic particles of very different sizes and atomic weights to be put in evidence within the organic matrix. On the basis of their analysis and elemental mapping by SEM-EDS (Fig. 15), quartz ( $\mathrm{Si}+\mathrm{O}$ ), ochers $(\mathrm{Fe}+\mathrm{O})$, alumina $(\mathrm{Al}+\mathrm{O})$, fine clay $(\mathrm{Al}+\mathrm{Si})$ and calcite $(\mathrm{Ca}+\mathrm{O})$ were identified. This result clearly showed that the mordant composition was more complex than first expected while looking at the fairly translucent aspect mordant has in stereoscopic micrographs (Fig. 14a). This suggests that the composition of the mordant might result from a waste drying oil reclaimed from the 'pincelière' (container where the brushes used in oil painting were put to soak in oil), the so-called 'or de couleur' according to Lebrun ${ }^{75}$ and Corneille. ${ }^{76}$ This size for oil gilding, quite viscous, was one of the most estimated, for its quicker drying during the gilding task. Although the accelerated chemical reaction of oil polymerization in the presence of metallic oxides was not understood at that time but only empirically verified, it was commonly employed by gilders over centuries $^{\mathbf{7 0}}$ until marketed products sold under the name of 'mixtion' appeared as ready-to-use mordants. ${ }^{77}$

4.4.3. Brown habit and brown hairs. Besides the finishing touches performed on the pedestals, the latest layer to have been applied to the statuettes concerns St. Francis' homespun. Aiming at giving the frock a homogeneous tone able to hide the different colour some casting parts may have had (as seen above - Fig. 3, back view of figurine E658), and a rough texture, a brown paint layer containing coarsely ground particles was applied to the garment overall surface (Fig. 3).

As far as the brown color is concerned, quite the same elements were detected by EDXRF on the saint's hair, beard and frock in both artworks (Fig. 10e and f): $\mathrm{S}, \mathrm{Pb}, \mathrm{K}, \mathrm{Ca}, \mathrm{Mn}, \mathrm{Fe}, \mathrm{Cu}$ and $\mathrm{Hg}$. The main difference between the figures' brown habit and brown hair lies in the fact that the artist made use of manganese dioxide in the frock but not in the hair, as shown in Fig. 10e and f. Elemental analysis, performed on the available frock sample areas (longitudinal sections) by SEM-EDS, was essential to put in evidence the presence of $\mathrm{Al}, \mathrm{Si}$ and $\mathrm{P}$, and to confirm the presence of $\mathrm{Cu}$ (Fig. 16); which raised the question about the use or not of aluminosilicates as fine clays, of bone black as a black pigment containing hydroxyapatite, and of a copper-based compound. Point analysis enabled the identification of manganese-rich tiny particles. Elemental mapping by SEM-EDS was essential to show the combination existing between these elements, and by comparison with color images 


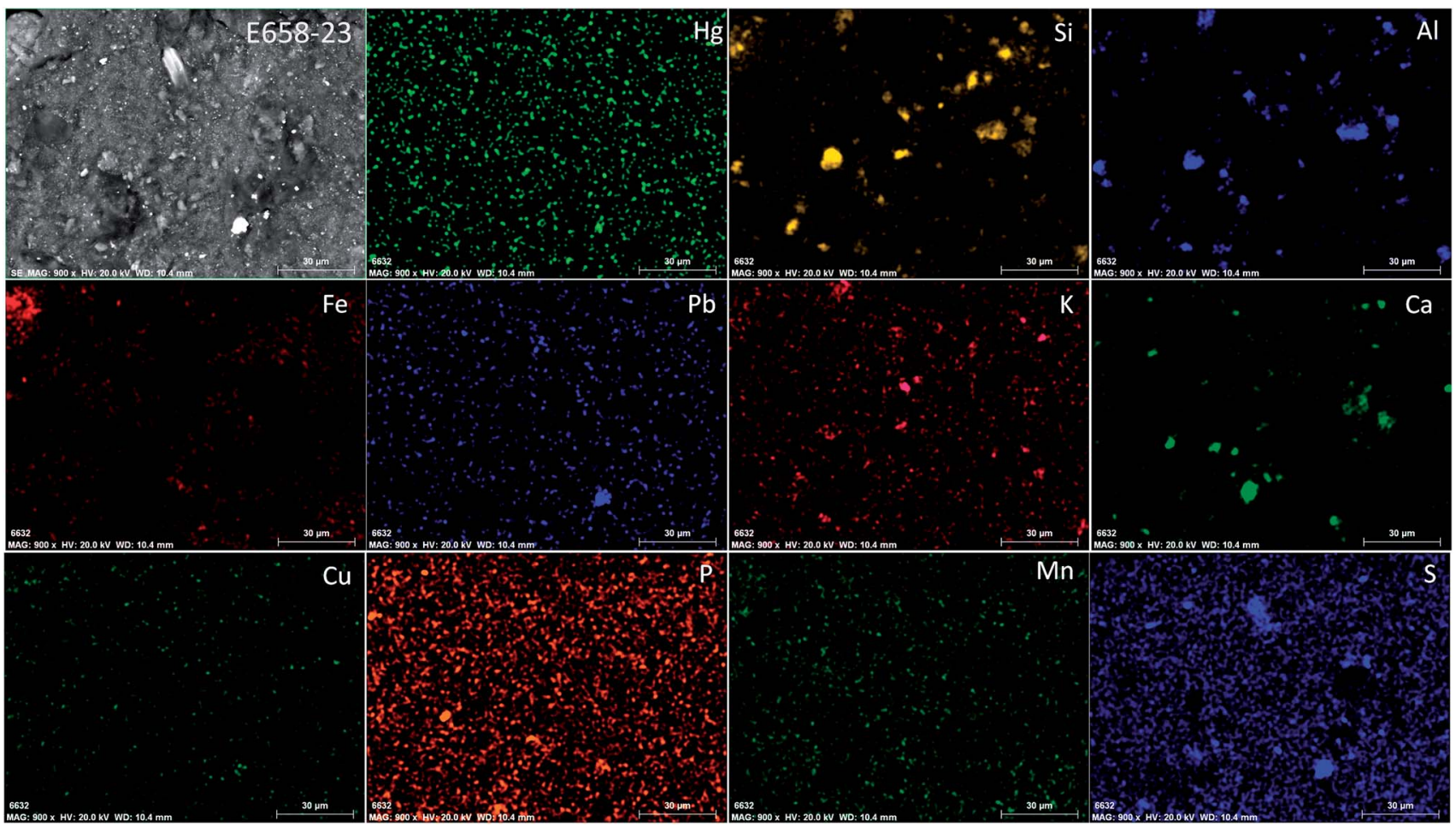

Fig. 16 Brown frock. Longitudinal section of sample E658-23 observed by SEM (BSE mode), 20 kV, $900 \times$, scale bar: $30 \mu$ m; and elemental mapping including the elements $\mathrm{Hg}, \mathrm{Si}, \mathrm{Al}, \mathrm{Fe}, \mathrm{Pb}, \mathrm{K}, \mathrm{Ca}, \mathrm{Cu}, \mathrm{P}, \mathrm{Mn}$ and $\mathrm{S}$.

of the same samples obtained by stereo-microscopy, to indicate the potential use of manganese dioxide $(\mathrm{Mn}+\mathrm{O})$, iron oxide and hydroxide $(\mathrm{Fe}+\mathrm{O})$, aluminosilicates $(\mathrm{Si}+\mathrm{Al})$, quartz $(\mathrm{Si}+\mathrm{O})$, bone black $(\mathrm{C}+\mathrm{P})$, vermilion $(\mathrm{Hg}+\mathrm{S})$, white lead $(\mathrm{Pb})$, calcium sulfate $(\mathrm{Ca}+\mathrm{S})$ and calcium carbonate (Ca alone). Micro-Raman partially succeeded in the identification of the coloring agents used to produce the brown shade, since no other spectra apart from vermilion, hematite and carbon black were obtained (Fig. 17). Further analysis carried out by $\mu$-XRD gave a partial complementary result, insofar as cerussite was the crystalline phase identified in one statuette (E657); the aforesaid $\beta$-cristobalite $\left(\mathrm{SiO}_{2}\right)$ was also found in both the frocks; and the unexpected presence of the above-mentioned lazurite plus diopside (E657) or haüyne (E658) was revealed in the brown batches of wax. A new outcome, in the form of hercynite (with the formula $\mathrm{FeAl}_{2} \mathrm{O}_{4}$ ) in statuette E658 (Table 5, sample E658-23), would tend to confirm the importance a metalworking workshop obviously had in the context of production of multiple wax-cast copies. Although hercynite is an iron aluminium oxide spinel mineral, it may also originate from dross (the technical term for iron slag) produced in the smelting processes of iron ores to be chemical and physically transformed into metal. ${ }^{78}$ In the present case-study, hercynite can be related to scories/slag, a waste product found in iron ore smelting sites, such as the one well established close to the S. Domingos mines ${ }^{79}$ and Torre de Moncorvo mines, in Portugal, or in furnaces from forge workshops for example. The fact that hercynite was not detected by $\mu$-Raman can be explained by the fact that the Raman lines are limited to $200 \mathrm{~cm}^{-1}$ and $800 \mathrm{~cm}^{-1}$, the intensities of which are reported to be weak. ${ }^{80,81}$
Although the presence of $\mathrm{Cu}$ in all EDXRF readings may be explained by the instrument setup, its detection within the micro-samples by SEM-EDS (as shown in Fig. 16) indicated that $\mathrm{Cu}$ originates from the artworks themselves, from one or more specific copper-based compounds: (a) from an impurity in the form of cuprite, a copper(1) oxide with the formula $\mathrm{Cu}_{2} \mathrm{O}$, associated with a variety of iron oxide minerals as it has been demonstrated for compounds sourced in Portugal ${ }^{82}$ and other regions of Europe. ${ }^{83,84}$ As the crystals of cuprite have a ruby-red to a nearly black shade, their presence would not interfere with the color of the pigment iron oxide, effectively used to give the

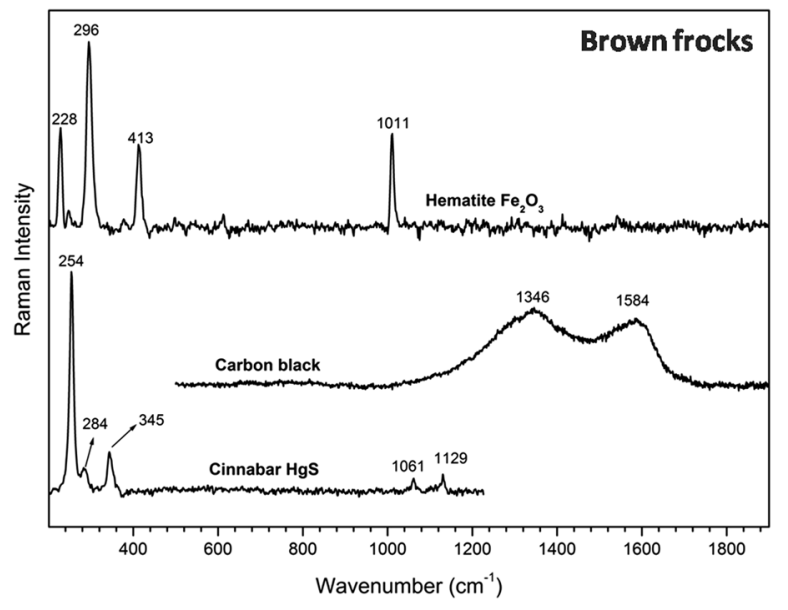

Fig. $17 \mu$-Raman spectra from the brown frocks. 
figurines' habit and hair their specific reddish brown tone. The presence of cuprite would indicate that the pigment red iron oxide would have been used in the raw or in a less refined form; (b) from another copper-based pigment intentionally mixed with the coloring matters already ascertained within the brown wax. It concerns the synthetic pigment called 'Hatchett's brown' or 'Prussian brown', a di-copper-hexacyanoferrate(II) hydrate $\left(\mathrm{Cu}_{2} \mathrm{Fe}(\mathrm{CN})_{6} \cdot x \mathrm{H}_{2} \mathrm{O}\right)$, commonly designated as copper ferrocyanide in the literature. ${ }^{62}$ The context of production of this artificial pigment is fairly known. It was synthesized by a certain $\mathrm{Mr}$ Jos. Humes in the later 18th century (maybe the latest two decades) but officially declared as a pigment suitable for painting in 1802 , by $\mathrm{Mr}$ Hatchett ${ }^{85}$ to whom the fabrication of the pigment was attributed. Because this information was widely disseminated in the subsequent years, ${ }^{\mathbf{8 6 , 8 7}}$ Humes asserted the discovery of the pigment in $1805^{88}$ but with no more success. In case the pigment di-copper-hexacyanoferrate(II) hydrate $\left(\mathrm{Cu}_{2} \mathrm{Fe}(\mathrm{CN})_{6} \cdot x \mathrm{H}_{2} \mathrm{O}\right)$ was effectively part of the admixture employed in the habit, its usage would constitute a terminus post quem and assist dating the statuettes, the production of which could have not occurred before the last quarter of the 18th century; (c) from a contaminating agent in the form of waste powdered copper, since filings were used to produce the core of the figurines' body. A more extended contamination might be also expected from impalpable copper dust present in the specific environment of a workshop specialized in metalworking. As for the blue veining evidencing the detection of $\mathrm{Cu}$, the analyses carried out in the brown areas provided no valid answer regarding copper.

By cross-checking these results, it appeared clearly that the colors of the brown areas were prepared with quite complex mixtures but difficult to ascertain, even by complementary spectroscopic techniques. It seems that the brown colors were obtained with a number of black matters, earth pigments ranging in color from dark brown to yellow, and vermilion. Although the former were numbered among the cheapest, ${ }^{77}$ some were well reputed such as the Portuguese ochers, ${ }^{49}$ and vermilion was part of the pigments particularly available in Portugal since earlier times. ${ }^{89}$ The white compounds (white lead, gypsum and calcite) were likely employed as fillers and opacifiers.

\subsection{Extra-materials}

4.5.1. Glass eyeballs. $X$-ray radiography put in evidence the insertion of eyeballs within the orbits (Fig. $7 b-d$ and $8 b$ ). These superadded devices are made of glass as it has been in usage in Portugal since the 17th century onwards, when 'postiche eyes' were used in polychrome sculpture to give the characters a more realistic stare (Fig. 7a and $8 \mathrm{a}$ ). ${ }^{90}$ In the two pairs of eyes considered in this research, each eyeball presents a peduncle. It corresponds to the stalk (or button) which ensured the proper connection of the molten glass to the pipe and remained on the working end of each ball after manufacture. A surprising result came out from the fact that the eyeballs are made of hand blown glass in statuette E657 and of solid molded glass in statuette E658.
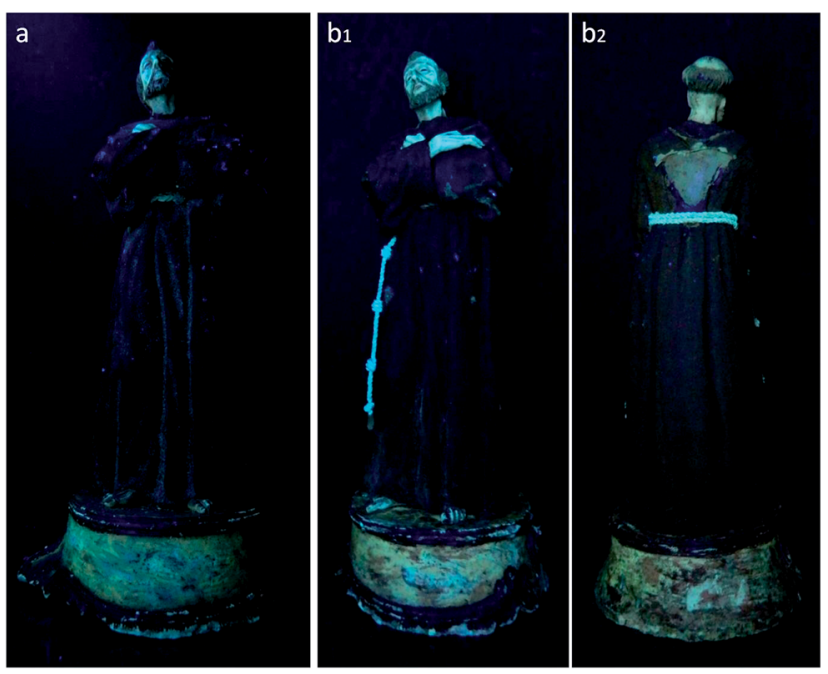

Fig. 18 Pair of figurines examined under UV illumination: (a) Figurine E657 front view; (b1) Figurine E658 front view; (b2) Figurine E658 back view.

In the former, the X-ray images put in evidence the void existing within the balls and the buttons, as shown by the difference of density in these elements (evidence accentuated while increasing the penetrative power of the beam) (Fig. 7b and c); while in the latter, the eyeballs and the buttons remained totally opaque to the radiation (Fig. 8b).

4.5.2. Thin twisted cord and fibers. Amongst the artefacts used to achieve the most astonishing likeness, the artist chose to imitate the knotted girdle the friar worn by using a similar material at a reduced scale (Fig. 1 and 3).

By also using materials coarsely ground in the brown surface of the figurines' frock to imitate a coarse woollen stuff, the artist clearly revealed his intent to produce a strong tactile effect, close to what one would expect of a true homespun garment (Fig. 3). However, this effect is achieved slightly differently. On figurine E657, natural fibers cut in little pieces were applied on the frock after the brown extra-coat application. As no binding medium seems to hold them in place, it was concluded that the coating underneath, richer in resins (already analyzed by GC/ MS, sample E658-3), was used at its tacky stage for the fibers to be attached at the very surface. This procedure proved to be certainly efficient on the short-term, but as most of the fibers have been rubbed away from the high points, the long term stability of this technique is questionable. The intentional absence of fibers on figurine E658, which should not be confused with such decay, was verified at high magnification and under UV illumination. The natural fibers that can be identified by their bluish fluorescence on figurine E657 are not present on figurine E658 (Fig. 18).

4.5.3. Varnish. Both pedestals have a glossy surface. While this could have been achieved as a result of a blending process used at the painting stage for the veining described above, or by polishing with a wet cloth, as described in the sources, ${ }^{2,3}$ it is in fact due to the application of a resin-based varnish. The resinous layer now appears slightly yellowish in hue due to its 
ageing (Fig. 11). Under UV radiation it has a greenish fluorescence (Fig. 18). The varnish is missing on E658 where a label was previously adhered (Fig. 18b2).

\section{Conclusions}

The complementary techniques set in this study proved suitable to have an overview on the way the two figurines were manufactured.

The results confirmed that the two figurines are the exact copies of a model. As much their casting as their assembly and finishing were based on the same technologies. Given that the materials used and their implementation are very similar at these three stages, it is reasonable to assert that the two objects were produced in the same workshop. The cast-material chosen for materializing the figurines, by using mixtures of beeswax, Venice Turpentine, other diterpenoid resins and a low amount of lipids, and the pigments and opacifiers used to color the different constitutive parts, conformed to the eighteenthcentury materials and recipes. The full range of coloring matters, ascertained by complementary analyses, points inorganic pigments perfectly known at that time and well registered in Portuguese sources: ${ }^{77}$ earth pigments including clays (ironrich alumino-silicates, referred under the generic term Bolo Armenia); hematite (red iron oxide, the so-called Almagre); yellow ochers (iron hydroxide, also designated as Ocar, available in the light and dark varieties); raw umber (manganese dioxide, referred to as Sombra or Sombra de Cintra); vermilion (literally Vermelhão); bone black (carbon-based pigment containing hydroxyapatite (recorded under both names of Negro de osso and Negro de marfim $^{91}$ ), white lead (here used in the form of cerussite and hydrocerussite, called Alvaiade), gypsum (Gesso), calcite or chalk (a more rarely mineral used in the palette, referred to as Giz or Cré), the latter white compounds having likely been employed as fillers and/or opacifiers. As to the finishing touches, perfectly effective means of representing the delicate St. Francis' complexion, the rough cloth and the polished marble-like pedestal were used to achieve the different textures and create a stronger contrast between poor and magestic materials. The techniques exactly met the astonishing realism that the Rococo period sought to produce.

In this study, a number of results may also seem rather unexpected, especially if the materials found are examined separately, but their detection makes sense while considered as a whole. On one hand, the presence of cristobalite in every batch of wax, of filings within the figurines' body, and of hercynite in one brown paste (sample E658-23), strongly relies upon materials originating from metallurgical activities, the former as a possible thermal alteration product of silica sand, the second as a waste material remaining from metalworking tasks, and the latter as iron slag. These findings are not so surprising in the context of production of the statuettes, in which molding, casting and foundry applications were basilar. On the other hand, the systematic detection of diverse grades of lazurite in every statuettes' constitutive parts, irrespective of their color, seems directly related to raw material handling or some type of recycling, likely of the wax employed in the 'dough' method to fabricate the mineral blue pigment lazurite. Bearing in mind the prohibitive cost of this genuine variety of ultramarine, its extent use would not make sense if it were not due to a contamination process. As neither evidence nor rational explanation was found regarding the presence of copper quite everywhere in the two figurines, one wonders until which point this element would also originate from some beeswax used in the lost-wax technique and in close contact with copper - thus another reclaimed material from other casting procedures; or from copper dust simply existing in the workshop environment. Anyway, all these practices seem to indicate a well organized workshop and valuable economic principles applied without affecting the aesthetic and durability of the final products.

Last but not least, in an eighteenth-century 'mass production' of figurines, based on multiple copies made of colored wax, it should be recalled that a rigorous division of tasks was expected to guarantee both quality and quantity. Such a production would rely upon the activity of, at least, a wax founder, an assembler and a painter - the latter taking also charge of gilding, according to the artistic trades and their regulations registered in Portugal since earlier times. ${ }^{\mathbf{9 2 - 9 4}}$ At this point, it seems that a distinct craftsman was indeed responsible for the casting and the assembling task, each one applying the same recipes and techniques in copies, as a matter of routine. Even so, regarding the finishing stage, every difference found on the two artworks - the veining of the marble-like pedestal painted blue (E657) or red (E658), the gold leaf of a higher (E657) or a lower (E658) grade, the final textured effect of the frock obtained with (E657) or without fibers (E658), and the use of hand-blown eyeballs (E657) or molded solid eyeballs (E658) suggests that each figurine was achieved by a different painter; and that each painter worked in a specific collaborative network, including at least a goldbeater and a glassmaker, to get supplies of the materials and accessories he needed from these crafts. Anyway, it will be difficult to be definite on whether the two figurines were part of the same batch or not, and which one was cast first. In fact, two hypotheses arose from this research: (1) the two copies resulted from an intense workshop activity at a given moment, thus involving several collaborations at the same time to produce one batch of dozens of copies; or (2) the two copies resulted from a smaller workshop with less outcomes but working over several years (if not decades), in which two painters may have been in charge one after another and were compelled to use the materials available at their time to achieve a batch on hand.

Irrespective of their time of production, the specific look of the figurines under study gives evidence of two possible plastic and chromatic versions of the same subject, certainly to meet a large demand and different tastes.

\section{Acknowledgements}

The authors are grateful to Ana Alcoforado, Director of Museu Nacional Machado de Castro (MNMC), Fernanda Alves and Pedro Ferrão (MNMC). They also thank Rui Silva, responsible for the Archives of the Direcção Geral do Património Cultural. Agnès Le Gac is greatly indebted to Pedro Sousa, for having produced the 
figurines' traditional X-radiographs on purpose for this research and for his dedicated collaboration.

\section{Notes and references}

1 M.-T. Baudry, Sculpture. Méthode et vocabulaire, Imprimerie Nationale, Paris, 1978.

2 N. Bondil, La Sculpture, art du modelage, Editions Fleurus Idées, Paris, 1996.

3 P. Clérin, La Sculpture. Toutes les techniques, Dessain-Tolra/ VUEF, Paris, 2001.

4 A. Le Gac, Imagem Brasileira 3, CEIB, Belo Horizonte-Minas Gerais, 2006, p. 41.

5 M. Regert, S. Colinart, L. Degrand and O. Decavallas, Archaeometry, 2001, 43(4), 549-569.

6 B. Cellini, Tratados de orfebrería y escultura [1565-7], tr, ed. J. C. Escobar, Ediciones Akal, Madrid, 1989.

7 I. D. P. Vasconcellos, Artefactos Symmetriacos e Geométricos, Officina Joseph-António Sylva, Lisboa Occidental, 1733.

8 A. Le Gac, M. Manso, S. Longelin, J. Bleton, L. Piorro, T. I. Madeira, A. Candeias, and M. L. Carvalho, Polychrome Sculpture: Artistic Tradition and Construction Techniques, ed. K. Seymour, ICOM-CC/Sculpture, Polychromy, and Architectural Decoration working group, 2014, p. 61.

9 Dicionário da arte barroca em Portugal, coord. J. F. Pereira, Editorial Presença, Lisboa, 1989.

10 Radiography of cultural material, ed. J. Lang and A. Middleton, Elsevier Butterworth Heinemann, Oxford, 2005, 2nd edn.

11 J. J. Rant, Z. Milič, P. Turk and I. Lengar, The 8th International Conference of the Slovenian Society for Non-Destructive Testing, Slovenia, 2005, 181, http://www.ndt.net/article/ndtslovenia2005/PAPERS/21-NDTP05-80.pdf.

12 M. I. Prudêncio, M. A. Stanojev Pereira, J. G. Marques, M. I. Dias, L. Esteves, C. I. Burbidge, M. J. Trindade and M. B. Albuquerque, J. Archaeol. Sci., 2011, 39(4), 964.

13 D. Mannes, S. Le Conte and E. Lehmann, Neutron vs. X-ray computed tomography: comparative study on the example of a violin, Report, 2010.

14 M. Gil, M. L. Carvalho, A. Seruya, I. Ribeiro, P. Alves, A. Guilherme, A. Cavaco, J. Mirão and A. Candeias, X-Ray Spectrom., 2008, 37, 328.

15 F. Rosi, A. Burnstock, K. J. Van den Berg, C. Miliani, B. G. Brunetti and A. Sgamellotti, Spectrochim. Acta, Part A, 2009, 71, 1655.

16 S. Pessanha, M. L. Carvalho, M. I. Cabaço, S. Valadas, J.-L. Bruneel, M. Besnard and M. I. Ribeiro, J. Raman Spectrosc., 2010, 41, 1220.

17 A. Le Gac, S. Pessanha, S. Longelin, M. Guerra, J. C. Frade, F. Lourenço, M. C. Serrano, M. Manso and M. L. Carvalho, Appl. Radiat. Isot., 2013, 82, 242.

18 L. G. Troalen, M. F. Guerra, J. Tate and B. Manley, ArcheoSciences, 2009, 33, 111.

19 A. Le Gac, R. Estrompa, A. Cardoso, A. Candeias, S. Pessanha, T. I. Madeira, J. Mirão, L. Dias and M. L. Carvalho, J. Anal. At. Spectrom., 2012, 27, 626.
20 A. Le Gac, I. Nogueira, M. Guerra, J. C. Frade, S. Longelin, M. Manso, S. Pessanha, A. I. Seruya and M. L. Carvalho, Microsc. Microanal., 2015, 21(1), 36.

21 M. P. Colombini and F. Modugno, Organic Mass Spectrometry in Art and Archaeology, John Wiley and Sons, Ldt, 2009.

22 I. Bonaduce and M. P. Colombini, J. Chromatogr. A, 2004, $1028(2), 297$.

23 M. Regert, J. Langlois and S. Colinart, J. Chromatogr. A, 2005, $1091,124$.

24 M. Regert, J. Langlois, E. Laval, A.-S. Le Hô and S. PagèsCamagna, Anal. Chim. Acta, 2006, 577(1), 140.

25 A. Tchapla, P. Mejanelle, J. Bleton and S. Goursaud, J. Sep. Sci., 2004, 27, 217.

26 A. Le Gac, Le Retable majeur de la Sé Velha de Coimbra et la polychromie dans le diocèse de Coimbra à l'époque baroque, Aspects techniques et esthétiques, $\mathrm{PhD}$ thesis, Universidade Nova de Lisboa, 2009, vols. 1 and 2, http://run.unl.pt/ bitstream/10362/4186/1/Arinto_2009.pdf.

27 G. D. Smith and R. J. H. Clark, Rev. Conserv., 2001, 2, 92.

28 P. Vandenabeele, H. G. M. Edwards and L. Moens, Chem. Rev., 2007, $107(3), 675$.

29 H. G. M. Edwards, D. W. Farwell, E. M. Newton, F. Rull Perez and S. Jorge Villar, J. Raman Spectrosc., 2000, 31, 407.

30 M. Sawczak, G. Śliwiński, A. Kaminska, M. Oujja, M. Castillejo, C. Domingo and M. Klossowska, Lasers in the Conservation of Artworks, ed. J. Nimmrichter, W. Kautech and M. Shreiner, Springer-Verlag, Berlin Heidelberg, 2007, p. 445 .

31 I. Aliatis, D. Bersani, P. P. Lottici and I. G. Marino, ArchéoSciences, 2012, 36, 7.

32 C. Suryanarayana and M. Grant Norton, X-Ray Diffraction: A Practical Approach, Plenum Press, New York, 1998.

33 A. Le Gac, A. I. Seruya, J. Bleton, S. Voduy and J. C. Frade, Technology and Interpretation Reflecting the Artist's Process, Archetype Publications, London, 2012, p. 90.

34 I. M. Bell, R. J. H. Clark and P. J. Gibbs, Spectrochim. Acta, Part A, 1997, 53, 2159.

35 H. G. M. Edwards, M. J. Falk, M. G. Sibley, J. Alvarez-Benedi and F. Rull, Spectrochim. Acta, Part A, 1998, 54, 903.

36 P. Vandenabeele, B. Wehling, L. Moens, H. Edwards, M. de Reu and G. Van Hooydonk, Anal. Chim. Acta, 2000, 407, 261.

37 L. Burgio and R. J. H. Clark, Spectrochim. Acta, Part A, 2001, 57, 1491.

38 Théophile, Diversarum Artium Schedula, [12th C.], tr. J. M. Guichard, Jacques Laget-Editions, Nogent-Le-Roi, 1996.

39 G. Vasari, Vasari on techniques [1550],tr. L. S. Maclehose, [s.n.], New-York, 1960.

40 Line engraving, September 2014, http:// www.antiqueprints.com/Info/engraving.php.

41 J. S. Mills and R. White, The Organic Chemistry of Museum Objects, Buttersworth, London, 1994.

42 K. Van den Berg, J. J. Boon, I. Pastorova and L. F. M. Spetter, J. Mass Spectrom., 2000, 35(4), 512.

43 [Anonimous], Segredos Necesarios para os Officios, Artes e Manufacturas, e para muitos objectos sobre a Economia domestica, Na Offic, de Simão Thaddeo Ferreira, Lisboa, 1794. 
44 A. Félibien, Des Principes de l'Architecture, de la Sculpture et de la Peinture, et des autres Arts qui en dépendent, avec un Dictionnaire propre à chacun de ces Arts, Chez Jean-Baptiste Coignard, Paris, 1676.

45 L. Jaucourt, L'Encyclopédie ou Dictionnaire raisonné des Arts et des Sciences, ed. D. Diderot and J. L. R. d'Alembert, Chez Briaçon, Paris, 1752, vol. 2, p. 472.

46 N. Lemery, Cours de Chymie, Chez Jean-Thomas Hérissant, Paris, 1675.

47 J. H. Henderson, M. L. Jackson, J. K. Syers, R. N. Clayton and R. W. Rex, Clays Clay Miner., 1971, 19, 229.

48 C. S. Sandford, J. Am. Ceram. Soc., 1935, 18(12), 149.

49 C. Cennini, Le Livre de l'art (Il libro dell'arte), [b. 1400], tr. C. Déroche, Editions Berger-Levrault, Paris, 1991.

50 M. P. Merrifield, Medieval and renaissance treatises on the art of painting. Original texts with English translations, Dover Publications Inc., Mineola, New York, 1967.

51 P. Nunes, Arte da Pintura. Symmetria, e Perspectiva, [1615], Intr. L. Ventura, Editorial Paisagem, Porto, 1982.

52 A. Palomino de Castro y Velasco, El Museo pictórico y escala óptica, Madrid, [1715], Editores Aguilar, Madrid, 1988.

53 B. Montón, Secretos de Artes Liberales, y Mecanicas, En casa de Maria Angela Marti Viuda, Barcelona, Madrid, 1734.

54 B. de Monton, Segredos das Artes Liberaes e Mecânicas. Seu author o Licenciado D. Bernardo de Monton, tr. J. Feyo Cerpa, Na Offic. de Domingos Gonçalves, Lisboa, 1744.

55 M. Serck-Dewaide, [et al./Belgium], M. Campoy Naranjo, [et al./Spain] and A. Le Gac [et al./Portugal], POLICROMIA, ed. A. I. Seruya, Instituto Português de Conservação e Restauro, Lisboa, 2004, p. 119.

56 C. Martel, On the Materials Used in Painting, with a Few Remarks on Varnishing and Cleaning Pictures, George Rowney \& Co., London, 1860.

57 T. W. Salter, Field's Chromatography; or, Treatise on Colours and Pigments as Used by Artists, Winsor and Newton, London, 1869.

58 C. Standage, The Artist's Manual of Pigments. Showing Their Composition, Conditions of Permanency, and NonPermanency, and Adulterations, Crosby, Lockwood and Son, London, 1896.

59 R. E. Wilde, S. N. Ghosh and B. J. Marshall, Inorg. Chem., 1970, 9(11), 2512.

60 B. H. Berrie, Artists' Pigments. A handbook of their history and characteristics, ed. E. W. FitzHugh, National Gallery of Art, Washington, 1997, vol. 3, p. 191.

61 L. Carlyle, The Artist's Assistant. Oil painting instruction manuals and handbooks in Britain 1800-1900, with reference to selected eighteenth-century sources, Archetype Publications, London, 2001.

62 N. Eastaugh, V. Walsh, T. Chaplin and R. Siddal, Pigment Compendium: A Dictionary and Optical Microscopy of Historical Pigments, Butterworth-Heinemann, Oxford, 2008.

63 A. K. Srivastava, S. R. Kishore and S. A. Agnihotry, Indian Journal of Engineering and Materials Sciences, 2004, 11, 315.

64 J. Plesters, Studies in Conservation, 1966, 11(2), 63.

65 J. Plesters, Artists' Pigments. A handbook of their history and characteristics, ed. A. Roy, National Gallery of Art,
Washington and Oxford University Press, Oxford, 1993, p. 37.

66 A. Kurella and I. Strauss, Maltechnic-Restauro, 1983, 89, 34.

67 D. Bomford, J. Brough and A. Roy, National Gallery Technical Bulletin, 1980, 4, 26.

68 B. Keisch and R. C. Callahan, Appl. Spectrosc., 1976, 30(5), 515.

69 J. Stalker and G. Parker, A Treatise of Japanning and Varnishing [1688], Tiranti, Berkshire, 2010.

70 J. F. Watin, l'Art du peintre, doreur, vernisseur [1778], Chez Léonce Laget, Paris, 1978.

71 D. de P. Brandão, Obra de talha dourada, ensamblagem e pintura na cidade e na diocese do Porto. Documentação IV, 1750-1800, [s.n.], Porto, 1985, vol. 4.

72 A. Le Gac, A. I. Seruya, M. Lefftz and A. Alarcão, ArcheoSciences, 2009, 33, 423, accessed 2014, http:// archeosciences.revues.org/2562.

73 D. Diderot and J. Le R. d'Alembert, Encyclopédie, ou dictionnaire raisonné des Sciences, des Arts et des Métiers, par une Société de gens de Lettres, Chez Briasson, David, Le Breton \& Durand, Paris, 1751-1758 [vol. I-VII], Chez Samuel Faulche \& Compagnie, Neufchastel, 1765 [vol. VIII-XVII].

74 J. Savary des Bruslons, Histoire du Commerce, Chez Jacques Estienne, Paris, 1730.

75 P. Lebrun, Recueil des Essaies des Merveilles de la Peinture [1635], M. P. Merrifield, Medieval and Renaissance Treatises on the Art of Painting. Original Texts with English Translations, Dover Publications Inc, Mineola, New York, 1967, p. 836.

76 T. Corneille, Dictionnaire des Arts \& des Sciences, Par M.D.C. de l'Académie Françoise, Chez Jean Baptiste Coignard et Chez la Veuve de Jean Baptiste Coignard, Paris, 1694, vol. 2, p. 137.

77 A. Le Gac, P. Oliveira, I. Dias Costa and M. J. Dias Costa, Making and Transforming Art: Technology and Interpretation, ed. H. Dubois, J. H. Townsend, J. Nadolny, S. Eyb-Green and S. Neven, Archetype Publications Ltd, London, 2014, p. 54.

78 A. Hauptmann, The Archaeometallurgy of Copper, Problems and Methods for Archaeometallurgy, Springer, Berlin Heidelberg, Berlin, 2007, p. 7.

79 L. Rosado, C. Morais, A. Candeias, A. P. Pinto, F. Guimarães and J. Mirão, Mineral. Mag., 2008, 72(1), 489.

80 F. Ospitali, T. Sabetta, F. Tullini, M. C. Nannetti and G. Di Lonardo, J. Raman Spectrosc., 2005, 36(1), 18.

81 M. Lübbe, A. M. Gigler, R. W. Stark and W. Moritz, Surf. Sci., 2010, 604, 679.

82 M. Gil, M. L. Carvalho, A. Seruya, A. Candeias, J. Mirão and I. Queralt, Nuclear Instruments and Methods in Physics Research A, 2007, 580, 728.

83 D. Hradil, T. Grygar, J. Hradilová and P. Bezdicka, Appl. Clay Sci., 2003, 22, 223.

84 A. Kirfel and K. Eichhorn, Acta Cryst., 1990, 46, 271.

85 C. Hatchett, Journals of the Royal Institution of Great Britain, 1802, 1, 306.

86 P. A. Adet, C.-L. Berthollet, M. E. Chevreul, P.-F. de Dietrich, A. F. de Fourcroy, H. V. Collet-Descotils, L. B. Guyton de Morveau, J. H. Hassenfratz, A. L. Lavoisier, G. Monge and J. L. Gay-Lussac, Annales de chimie ou recueil de mémoires 
concernant la chimie et les arts qui en dependent, Chez Fuces Libraire, Paris, 1803, [An XI], vol. 46, p. 168.

87 R. O'Reilly and J.-N. Barbier-Vémars, Annales des Arts et Manufactures, Chez Chaignieau aîné Imprimeur-Libraire, Paris, 1813, vol. 12, p. 232.

88 A. Tilloch, The Philosophical Magazine, R. Taylor and Co, London, 1805, p. 142.

89 A. Le Gac, J. Silva, S. Fragoso, S. Pessanha, M. Manso, S. Longelin, L. Esteves, M. J. Oliveira, A. Candeias, L. Pereira and M. L. Carvalho, 500 Anos do Foral Manuelino de Cascais, Câmara Municipal de Cascais, Cascais, 2014, p. 152.

90 M. R. E. Quites and G. F. de Medeiros, Anais do VIII Congresso da ABRACOR-Associação Brasileira de Conservadores
Restauradores de Bens Culturais, ABRACOR Edition, OuroPreto/Brasil, 1996, p. 189.

91 A. J. Cruz, Instituto de História da Arte da Faculdade de Letras da Universidade de Lisboa, Artis, 2009, 7-8, 385.

92 V. Correia, Livro dos Regimetos dos Officiaes mecanicos da mui nobre e sepre leal cidade de Lixboa [1572], Imprensa da Universidade, Coimbra, 1926.

93 F.-P. Langhans, As corporações dos ofícios mecânicos. Subsídios para a sua história, Imprensa Nacional de Lisboa, Lisboa, 1946.

94 A. Le Gac, Frei Cipriano da Cruz em Coimbra, eds. A. Le Gac and A. Alcoforado, Coimbra-Capital-Nacional-da-Cultura, Coimbra, 2003, vol. V, p. 95. 